Federal Reserve Bank of New York

Staff Reports

\title{
Watering a Lemon Tree: \\ Heterogeneous Risk Taking and Monetary Policy Transmission
}

\author{
Dong Beom Choi \\ Thomas M. Eisenbach \\ Tanju Yorulmazer
}

Staff Report No. 724

April 2015

Revised April 2020

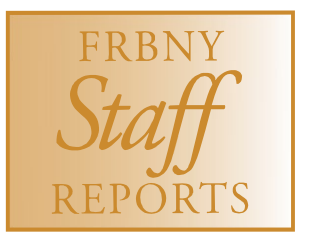

This paper presents preliminary findings and is being distributed to economists and other interested readers solely to stimulate discussion and elicit comments. The views expressed in this paper are those of the authors and do not necessarily reflect the position of the Federal Reserve Bank of New York or the Federal Reserve System. Any errors or omissions are the responsibility of the authors. 
Watering a Lemon Tree: Heterogeneous Risk Taking and Monetary Policy Transmission

Dong Beom Choi, Thomas M. Eisenbach and Tanju Yorulmazer

Federal Reserve Bank of New York Staff Reports, no. 724

April 2015, revised April 2020

JEL classification: E52, E58, G20

\begin{abstract}
We build a general equilibrium model with financial frictions that impede monetary policy transmission. Agents with heterogeneous productivity can increase investment by levering up, which increases liquidity risk due to maturity transformation. In equilibrium, more productive agents choose higher leverage than less productive agents, which exposes the more productive agents to greater liquidity risk and makes their investment less responsive to interest rate changes. When monetary policy reduces interest rates, aggregate investment quality deteriorates, which blunts the monetary stimulus and decreases asset liquidation values. This, in turn, reduces loan demand, decreasing the interest rate further and generating a negative spiral. Overall, the allocation of credit is distorted and monetary stimulus can become ineffective even with significant interest rate drops.
\end{abstract}

Key words: monetary policy transmission, financial frictions, heterogeneous agents, financial intermediation

Eisenbach: Federal Reserve Bank of New York (email: thomas.eisenbach@ny.frb.org). Choi: Seoul National University (email: dong.choi@snu.ac.kr). Yorulmazer: University of Amsterdam (email: t.yorulmazer@uva.nl). For helpful comments, the authors thank Viral Acharya, Tobias Adrian, Gara Afonso, Onur Altindag, Adrien Auclert, Markus Brunnermeier, Charles Calomiris, Eduardo Davila, Mark Flannery, Douglas Gale, Itay Goldstein, Burton Hollifield (discussant), Sebastian Infante (discussant), Charles Kahn, David Martinez Miera, Konstantin Milbradt, Christian Opp (discussant), Enrico Perotti, Jean-Charles Rochet, Tano Santos, Eva Schliephake (discussant), Andrea Tambalotti, Jenny Tang (discussant), Sergio Vicente, James Vickery, Vish Viswanathan, Cindy Vojtech (discussant), and Zhenyu Wang, as well as audiences at the New York Fed, the System Committee Conference on Macroeconomics, the University of Amsterdam, the New York Fed/NYU Joint Conference on Financial Intermediation, FIRS, Mitsui Finance Symposium, EFA, the Princeton Trinity of Stability Conference, Cass Business School, the German Economists Abroad Conference, the Workshop on Corporate Control and Governance at the SKEMA Business School, the Barcelona GSE Summer Forum, the Bank of Canada Workshop on Advancements in Economic Modeling, Universidad Carlos III de Madrid, the University of British Columbia, Rutgers University, HEC Paris, Tilburg, and Copenhagen Business School. Any errors are the authors' own. The views expressed in this paper are those of the authors and do not necessarily represent the position of the Federal Reserve Bank of New York or the Federal Reserve System.

To view the authors' disclosure statements, visit https://www.newyorkfed.org/research/staff_reports/sr724.html. 


\section{Introduction}

The run-up to the recent financial crisis as well as its aftermath have focused attention on the interaction of monetary policy and financial stability. An important element highlighted by policy makers is how much maturity and liquidity transformation financial intermediaries engage in (Stein, 2014; Tarullo, 2014). This decision is affected by monetary policy in ways that are important for both financial stability as well as the transmission of monetary policy itself.

In this paper, we investigate how financial frictions inherent in maturity transformation can impede the effectiveness of monetary policy in trying to stimulate investment. We build a general equilibrium model with heterogeneous agents and show how strong financial frictions can lead to heterogeneous responses to changes in monetary policy, both directly and through feedback effects. Monetary stimulus in the face of financial frictions results in risk taking by less productive agents, which significantly impairs the transmission of monetary stimulus. Aggregate output can become unresponsive to monetary stimulus due to a feedback between investment quality deterioration in response to the lower interest rate and decreased aggregate loan demand further lowering the interest rate. This leads to inefficient credit reallocation in the economy, since funds are shifted away from more productive agents to less productive ones. For understanding the postcrisis period of sluggish growth despite substantial monetary loosening, our mechanism is therefore different from the conventional liquidity trap in which output becomes unresponsive to monetary stimulus because the interest rate becomes unresponsive at the zero lower bound. It is also distinct from "reaching for yield" that results from compressed net interest margins because, in our setting, loose monetary policy in principle increases the profitability of maturity transformation.

The model features heterogeneous agents that borrow short-term to invest long term and that differ in their constant-returns-to-scale investment productivity. As we focus on frictions originating from maturity transformation, we effectively collapse a financial intermediary and a firm into one agent, assuming no financial or informational friction between the two. In the first-best case, without any financial frictions, only the most productive agent would borrow and invest-absorbing all the available funds-which would maximize aggregate output in this economy. However, the presence of frictions in our model disrupts the efficiency of credit allocation. As a first friction, we assume that borrowing comes with interim liquidity risk, as is standard in financial intermediation with maturity transformation. Investment projects are long-term but borrowing is short-term such that borrowers are subject to liquidity shocks at an interim date. When hit by the shock, a 
borrower has to liquidate her assets in the secondary market at a discount.

The probability of a liquidity shock is higher for a borrower with more leverage, thus ex-ante liquidity risk increases as borrowers lever up. This implies that the marginal cost of borrowing due to liquidity risk grows as a borrower's leverage increases, pushing the allocation away from the first-best. In equilibrium, each borrower equates the marginal excess return of her project to the marginal cost of liquidity risk. Since more productive agents have higher excess returns, they can afford to take on more liquidity risk and, as a result, they borrow more and invest more in equilibrium.

Our novel effects arise from the fact that, for given equilibrium values of interest rate and secondary market liquidation value, each borrower is at a type-specific interior optimum. When monetary policy leads to changes in these equilibrium values, different borrower types respond heterogeneously in adjusting their leverage, which leads to a change in the distribution of investment across types and therefore affects the aggregate response to the policy.

As all agents in our model are risk neutral and have rational expectations, every borrower pays the risk free interest rate in expectation and a change in that rate has the same effect on every borrower type's first order condition. However, high productivity types endogenously face a higher marginal cost of liquidity risk and therefore adjust their borrowing less to changes in the interest rate than low productivity types. In contrast, due to high types' greater exposure to liquidity risk, a change in the liquidation value has a bigger effect on high types' first order condition. This can lead high types to adjust their borrowing more to changes in the liquidation value than low types-in contrast to the response to the interest rate.

Figure 1 illustrates the general equilibrium mechanisms of the model. When the central bank provides monetary stimulus by injecting more funds, the market clearing interest rate drops, leading to an increase in investment which has a standard positive effect on output (black arrows). In our model, however, the quality of investment changes since agents with different investment productivity respond heterogeneously to the interest rate drop. Since high types are already more exposed to liquidity risk, they are more reluctant to lever up further. Overall, the direct effect of a decrease in the interest rate is therefore a shift in the distribution of investment towards low types so the average quality of investment in the economy worsens which has a negative effect on output (blue arrows).

In addition, the shift in investment towards low types opens the door for indirect feedback effects when we introduce our second financial friction: asymmetric information in the secondary market for liquidated assets such that the liquidation value depends on the overall quality of assets sold. With this lemons pricing, e.g., due to opaqueness or com- 


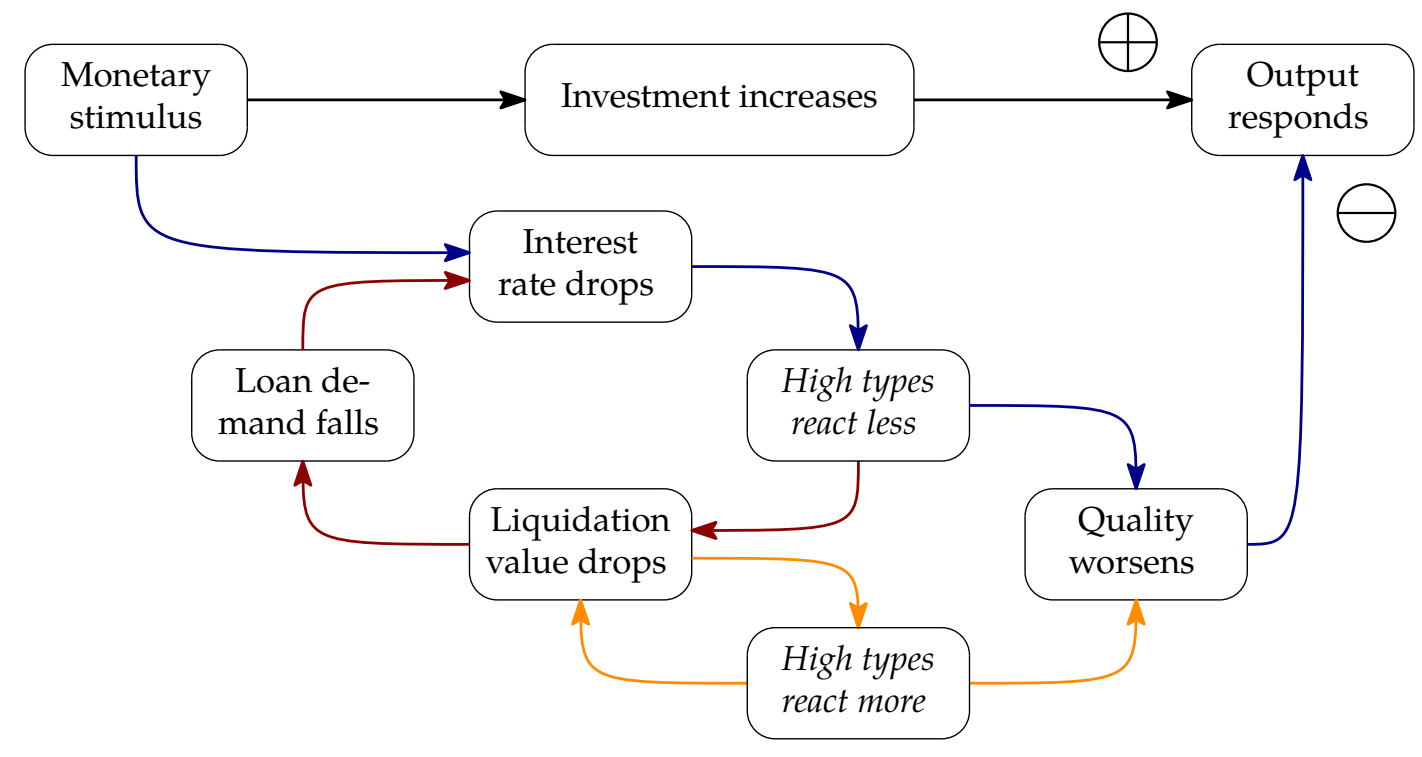

Figure 1: Negative feedback spirals dampening the effect of monetary policy

plexity of the underlying assets, the heterogeneous response to monetary stimulus leads to a drop in the equilibrium liquidation value. This raises the cost of being hit by a liquidity shock and reduces all borrowers' demand for funds, causing a feedback loop of further downward pressure on the interest rate (red arrows). In addition, the drop in the liquidation value affects the trade-off between investment return and liquidity risk, and does so more for high types. Thus, high types can react more to the liquidation value than low types, so that quality deteriorates further (orange arrows) and a lemons spiral arises.

In this feedback process, the overall quality of investment deteriorates significantly as funds are reallocated from high types toward low types. Overall, monetary stimulus can therefore lead to a large drop in the interest rate but only a small increase (or potentially even a decrease) in aggregate output due to the composition of investment changing from agents with high productivity to agents with low productivity. Our model therefore helps understand the weak monetary policy transmission concurrent with low-quality investment and increased maturity mismatch.

Our model does not specifically distinguish monetary stimulus and tightening. However, the quality effect in the transmission mechanism should not be thought of as symmetric for stimulus and tightening since the macroeconomic contexts-captured by the exogenous parameters in our model - for the two scenarios are different. Our mechanism critically depends on financial frictions, in particular endogenously increasing cost of leverage and secondary market frictions. Both of these frictions should not be assumed constant over the business cycle but rather more severe in downturns (in particular during a crisis) 
than in upturns. In our specific setup, the liquidity risk underlying the heterogeneous responses and therefore the dampened transmission of monetary policy are more relevant during downturns.

In an extension of the model, we show that the lemons pricing is not essential for our results. In particular, we analyze the case where the buyers can distinguish the individual assets in the secondary market but the cash in the secondary market is limited, e.g., due to limited participation (Allen and Gale, 1994, 1998). This, in turn, leads to cash-in-themarket pricing and we show that even in this setup monetary stimulus gets dampened due to liquidity risk and the heterogeneous response of agents.

Related literature: Our setup differs in three important ways from other theoretical papers in the literature on bank lending and monetary policy. First, we have a constantreturns-to-scale production technology so that there is no shortage of good projects in the economy. Second, our model does not feature agency problems, e.g., arising from limited liability, deposit insurance and the possibility of forbearance and bailouts, that are typical in models of banking. ${ }^{1}$ Third, in our model liquidations are not inherently inefficient. Even without such assumptions, our model generates welfare losses through changes in the composition of investment by different types.

This paper is related to a recent literature that focuses on the role of heterogeneous agents in the transmission of monetary policy. Di Maggio et al. (2015) and Keys et al. (2014) analyze the consumption responses of heterogeneously indebted households, while Ippolito et al. (2015) focus on firms with different levels of bank debt. Auclert (2015) provides a theoretical model with agents heterogeneously exposed to interest rate risk and study the monetary policy transmission in general equilibrium. Sufi (2015) provides a literature review on recent findings, emphasizing the importance of "redistribution channels of monetary policy."

While these papers focus on the transmission through households or firms, our paper focuses on the endogenous allocation of credit and analyzes how introducing heterogeneity changes the efficiency implications of monetary policy. ${ }^{2}$ In that regard, it is related to the literature on the credit channel of monetary policy. Our mechanism is different from

\footnotetext{
${ }^{1}$ Acharya and Thakor (2016) show that banks use excessive leverage because they ignore liquidation externalities, and the blanket regulatory forbearance when dealing with contagious liquidations destroys market discipline. Acharya and Yorulmazer (2007) and Farhi and Tirole (2012) highlight the role of collective moral hazard in case of bailouts.

${ }^{2}$ In a recent paper, Agarwal et al. (2015) find that bank-mediated stimulus was less effective during the Great Recession due to inefficient pass-through leading to credit misallocation. They argue that facing a reduction of funding costs, banks extended additional credit to the agents with lower marginal propensity to borrow, due to concern about asymmetric information problems.
} 
the standard balance sheet channel (e.g., Bernanke and Gertler 1989, 1995) in which an external finance premium resulting from agency problems is the main driver. In that case, monetary policy has an amplifying effect since it relaxes the financial constraints of borrowers, whereas in our case there are no agency problems and a dampening effect arises. Thus, agents in a standard setup face binding financial constraints and the shadow costs of capital are different across agents in equilibrium. In our setup, agents are making an unconstrained decision and thus the marginal costs of capital are equalized in equilibrium. In addition, since we assume constant returns to scale for each agent there is no lack of good projects.

Our paper is more closely related to the literature on the bank lending channel of monetary policy (Bernanke and Blinder, 1992; Kashyap and Stein, 2000). For example, Gambacorta and Shin (2018) have shown empirically that bank leverage matters for monetary policy in the sense that a 1 percentage point increase in equity to total assets leads to a 4 basis point decrease in the cost of funds and 0.6 percentage point increase in annual lending growth. Our model presents a novel distortion of monetary transmission within a bank lending channel driven by heterogeneous agents' endogenously chosen risk exposures that consequently limit debt capacity. Thakor (1996) finds, theoretically and empirically, that monetary stimulus can paradoxically decrease bank lending when capital requirements are linked only to credit risk, and Benmelech and Bergman (2012) show theoretically how the real economy becomes unresponsive to monetary stimulus due to financial frictions in credit intermediation. Our distinction between "quality" and "quantity" of lending is also related to the literature on the risk taking channel of monetary policy (for an overview, see Borio and Zhu, 2012; De Nicolò et al., 2010; Adrian and Shin, 2010), although our focus is on productivity rather than credit risks. Empirical evidence relating monetary loosening and quality deterioration is documented by Ioannidou et al. (2015), Altunbas and Marques-Ibanez (2014), Peydró and Maddaloni (2011), Paligorova and Santos (2012), Dell'Ariccia et al. (2016), and Jiménez et al. (2014). Analyzing the theoretical mechanism of this quality deterioration, Dell'Ariccia et al. (2014) argue that monetary loosening decreases banks' monitoring efforts due to their increase in leverage. Acharya and Naqvi (2019) provide a model in which monetary loosening induces banks' reach for yield by reducing the cost of liquidity shortfalls. Unlike the existing papers that examine a "representative" bank, our innovation is to introduce heterogeneous banks to analyze the credit misallocation through the distributional changes.

Our paper is also related to the literature on maturity structure of debt and the associated fragility that arises ${ }^{3}$ as well as the literature on fire sales and costly liquidation of

\footnotetext{
${ }^{3}$ See for example Diamond and Dybvig (1983); Flannery (1986); Diamond (1991); Calomiris and Kahn
} 
assets. ${ }^{4}$ However, as mentioned above, in contrast to other banking models with costly liquidation, we assume that interim liquidations do not result in any direct welfare losses but only amount to transfers between agents. Hence, our inefficiency is entirely driven by disruptions in the allocation of credit across heterogeneous agents, i.e. the redistribution of investment from high to low productivity agents.

Finally, our paper contributes to the broad literature on incorporating financial frictions into macroeconomic analysis. In particular, we analyze how frictions in the secondary market generate macro effects. Kiyotaki and Moore (1997) study the effect of resalability of financial assets in secondary markets on aggregate investment, and Kurlat (2013) builds a model in which this friction comes from a lemons problem in the secondary market. Bolton et al. (2011) and Malherbe (2014) also study an economy in which incomplete information in the secondary market affects investment decisions. For a general review, see, e.g., Brunnermeier et al. (2013).

The paper is organized as follows. Section 2 discusses the model setup. Section 3 analyzes the leverage and investment decisions of individual agents, as well as the effects of interest rates and asset prices on such choices. Section 4 analyzes the mechanism of monetary transmission impairment in a general equilibrium setup. Section 5 illustrates the model with a numerical example. Section 6 discusses extensions and Section 7 concludes.

\section{Model setup}

Primitives: Consider a model with three dates $t=0,1,2$. There are two groups of agents: borrowers and lenders. All agents are risk neutral and have discount factors of 1 . At $t=0$, borrowers have an investment opportunity and an initial endowment equal to $e$, while lenders have an endowment of $E$ but do not have investment opportunities. Lenders are homogeneous with measure 1 and among borrowers, we have two types, high and low, denoted by $i=h, \ell$, each with measure $1 .^{5}$ The only difference between the two types of borrowers is their access to a type-specific investment technology with constant returns to scale; a unit investment by type $i$ at $t=0$ pays off a return $R_{i}$ at $t=2$. We assume that $R_{h}>R_{\ell}>1$ so that both types' investment is productive but there is heterogeneous productivity across agents. Since type $h$ has a higher return, the first-best allocation would

(1991); Diamond and Rajan (2001); Brunnermeier and Yogo (2009); Brunnermeier and Oehmke (2013).

${ }^{4}$ See for example Williamson (1988); James (1991); Shleifer and Vishny (1992); Allen and Gale (1994, 1998); Pulvino (1998); Acharya et al. (2006); Coval and Stafford (2007); Shin (2009); Ellul et al. (2011). Shleifer and Vishny (2011) provide a survey.

${ }^{5}$ This setup is for simplicity and we could generalize the number of types as well as the distribution of types and of endowments. 
require that all the funds in the economy are invested by the high types. Assuming constant returns to scale is important to ensure that our dampening effects are not driven by an exogenous technology but by the endogenous behavior of agents. Note that, for simplicity, there is no fundamental risk in the agents' projects.

We collapse a financial intermediary and a firm borrowing from that intermediary into a single economic agent (see, e.g., Stein, 2012, and Brunnermeier and Sannikov, 2014, for models that take a similar approach). This simplification implies that we assume no financial or informational friction between the bank and the borrowing firm (e.g., screening and monitoring frictions or agency problems of the firms), so that we can focus on the frictions originating in financial intermediaries' maturity transformation. Different types of borrowers in our model can thus be considered as banks that have lending opportunities with different linear returns.

Borrowing/lending: At $t=0$, agents with profitable opportunities can invest more than their own endowment $e$ by borrowing from the lenders in the loanable funds market. For simplicity, we only consider debt financing for the additional investment. Appendix D studies the case when we allow equity $e$ to be endogenous. Since the seminal paper by Myers and Majluf (1984), a range of models explain endogenous debt financing that dominates costly equity financing. Subsequent literature justifies debt for reasons such as adverse selection (Nachman and Noe, 1994; DeMarzo and Duffie, 1999; Dang et al., 2012), moral hazard (Innes, 1990), costly state verification (Townsend, 1979; Gale and Hellwig, 1985) and various explanations based on controlling or limiting investment (Jensen, 1986; Aghion and Bolton, 1992; Hart and Moore, 1994).

Lenders are competitive and their outside option is the risk-free rate $r$. A borrower of type $i$ borrows at a type-specific interest rate $r_{i}$, which is determined endogenously to guarantee that all lenders receive the risk-free rate $r$ in expectation. Since there is credit risk, the promised interest rate will be greater than the risk free rate, $r_{i} \geq r$. For details, see Lemma 1 and its proof in Appendix A. Because debt is fairly priced, our results are not driven by distortions such as deposit insurance or agency problems, which are common in other models with financial intermediation. ${ }^{6}$ The risk-free rate $r$, in turn, is determined endogenously by market clearing in the market for loanable funds at $t=0$. We focus on equilibria with $1+r<R_{\ell}$ so that both types have a high enough long-term return from the investment to cover the expected funding cost. ${ }^{7}$

\footnotetext{
${ }^{6}$ See, e.g., Stiglitz and Weiss (1981), and Acharya and Viswanathan (2011) for models of credit rationing in the presence of asymmetric information and agency problems.

${ }^{7}$ This is without loss of generality as it corresponds to focusing on the intensive margin effects among agents with $R_{i}>1+r$ in a more general model with more than two types. Any additional extensive margin
} 
Let $D_{i}$ denote the amount type $i$ borrows at $t=0$ and define type $i$ 's leverage as $b_{i} \equiv$ $\left(D_{i}+e\right) / e$. Total investment in this economy at $t=0$ can be written as

$$
I=\left(D_{h}+e\right)+\left(D_{\ell}+e\right)
$$

Taking the heterogeneous productivity into account, the average quality of investment as measured by its productivity is given by

$$
q=\frac{R_{h}\left(D_{h}+e\right)+R_{\ell}\left(D_{\ell}+e\right)}{\left(D_{h}+e\right)+\left(D_{\ell}+e\right)}=\frac{R_{h} b_{h}+R_{\ell} b_{\ell}}{b_{h}+b_{\ell}}
$$

which depends on the distribution of $D_{i}$ or, equivalently, $b_{i}$ across the two types.

Liquidity risk: The key friction in our setup is that borrowers face liquidity risk-a possible creditor run-in the interim period $t=1$ and that this risk is an increasing function of leverage. When experiencing a run, a borrower is forced to liquidate the long-term assets in a secondary market at a discount, which is costly for the borrower. Thus debt becomes endogenously more costly to the borrower as she increases leverage, although its expected rate of return to the lender stays constant at $r$.

We assume that all debt is short-term and needs to be rolled over at $t=1$, which is a typical maturity-mismatch problem that financial institutions face. We assume that the likelihood of a borrower facing a run and not being able to replace the lost funding is increasing in the borrower's leverage. ${ }^{8}$ Such a positive relationship between the leverage of a borrower with maturity mismatch and its exposure to the risk of a liquidity shock is common in theoretical micro-foundations of runs, both fundamentals- and panic-based. It is also consistent with empirical evidence. In particular, Pérignon et al. (2018) show that banks with higher leverage are more likely to experience short-term funding dryups and Berger and Bouwman (2013) show that banks with higher leverage have a higher probability of failure, especially during financial crises.

We denote by $\alpha(b)$ the ex-ante, as of $t=0$, probability that a borrower with leverage $b$ experiences a liquidity shock at $t=1$ and assume that the liquidity risk $\alpha(b)$ is increasing, $\alpha^{\prime}(b)>0 .{ }^{9}$ To guarantee an interior solution for optimal leverage, we require that liquidity risk is weakly convex, $\alpha^{\prime \prime}(b) \geq 0$, and to keep the analysis intuitive, we rule out third or-

effects would strengthen our results (i.e., borrowers with low $R_{i}$ become active and start investing when they did not invest before a drop in $r$ ).

${ }^{8}$ We assume that it is not possible to raise equity when facing a run at $t=1$, as is standard in the literature. See, e.g., Hanson, Kashyap, and Stein (2011) for a review.

${ }^{9}$ Kashyap et al. (2014) adopt a similar reduced-form setup where interim liquidity risk is captured by ex-ante probability of a liquidity shock, which is a function of balance-sheet variables. 
der effects, $\alpha^{\prime \prime \prime}(b) \approx 0 .{ }^{10}$ We provide two microfoundations for an $\alpha$ with these features in Appendix B.1. In the first, a random fraction of creditors has early consumption needs and if this fraction and the resulting withdrawal is too high, the borrower fails and is forced to liquidate. In the second, based on a global games setting, creditors receive i.i.d. noisy signals about borrower-specific project uncertainty and withdraw for sufficiently bad signals. In both settings, the probability of the borrower being forced into liquidation is increasing in the vulnerability of the borrower to withdrawals which, in turn, is increasing in leverage $b$. Both of our microfoundations result in the same $\alpha$ for the liquidity risk of both types $i=h, \ell$. As we discuss in Section 6.2 and Appendix B.2, all our results go through when we allow for type-specific liquidity risk.

Liquidation value: Our second financial friction is in the secondary market where borrowers facing a liquidity shock at $t=1$ have to liquidate their assets. We assume lemons pricing due to incomplete information such that $P=\delta \times Q$ where $Q$ is the average quality of the assets being liquidated in the secondary market and $\delta<1$ is a discount factor. ${ }^{11}$ We discuss these two elements of $P$ in turn.

First, the average quality $Q$ is given by

$$
Q=\frac{\sum_{i=h, \ell} \alpha\left(b_{i}\right) R_{i}\left(D_{i}+e\right)}{\sum_{i=h, \ell} \alpha\left(b_{i}\right)\left(D_{i}+e\right)}=\frac{\sum_{i=h, \ell} \alpha\left(b_{i}\right) R_{i} b_{i}}{\sum_{i=h, \ell} \alpha\left(b_{i}\right) b_{i}},
$$

where the denominator characterizes the amount of liquidated assets, and the numerator characterizes long-term output from the liquidated assets. Assuming that all sellers face the same price based on average quality $Q$ implies that potential buyers cannot distinguish the individual quality of the liquidated assets in the secondary market at $t=1$. This is in contrast to the debt market at $t=0$, where lenders charge an interest rate $r_{i}$ that depends on the type of the borrower. ${ }^{12}$ Our intuition for this difference in the lending market at $t=0$ and the assets market at $t=1$ is as follows. At $t=1$, we think of fire sales, where many assets are sold quickly at the same time in a disorderly manner. Hence, there may be a limited number of buyers who can distinguish the quality of the assets and have the financial capacity to acquire them; as a result, assets may have to be acquired by

\footnotetext{
${ }^{10}$ Our results go through under the weaker condition that $(\alpha(b) b)^{\prime \prime}=\alpha^{\prime \prime}(b) b+2 \alpha^{\prime}(b)$ is positive and that $(\alpha(b) b)^{\prime \prime \prime}=\alpha^{\prime \prime \prime}(b) b+3 \alpha^{\prime \prime}(b)$ is nonnegative.

${ }^{11}$ See Bolton, Santos, and Scheinkman (2011) for a model where the asset price is similarly based on average quality and discounted due to the limited cash held by long-run investors.

${ }^{12}$ Note that $r_{i}$ depends not directly on $i$ 's type $h$ or $\ell$ but only indirectly through $D_{i}$. See the proof of Lemma 1 for details.
} 
buyers who cannot distinguish their quality (Shleifer and Vishny, 1992). ${ }^{13}$ In contrast, at $t=0$, lenders have enough time and resources to conduct the necessary analysis and the due diligence to distinguish different types of borrowers so that they can charge different interest rates $r_{i}$ for different type of borrowers.

Second, assets are liquidated at a discount rate $1-\delta$ relative to their average fundamental value. We assume that $\delta$ is sufficiently small to ensure that $P=\delta \times Q<1+r$ such that liquidation is costly for all borrowers. This assumption implies that all sales are forced and there is no classic adverse selection at $t=1$ in the sense that agents choose to sell assets when not necessary. We hence rule out situations where low type agents borrow at $t=0$ with the only intent to sell all their assets at $t=1$. See Malherbe (2014) for a model with classic adverse selection where low types strategically liquidate their assets, resulting in hoarding of cash and self-fulfilling liquidity dry-ups.

Importantly, we do not assume that any final output is lost through the secondary market liquidation process; the difference between expected fundamental value and liquidation value, i.e., $(1-\delta) Q$, is simply a transfer. This implies that the dampening effect we show is not due to resources lost in inefficient liquidation; the effect is due purely to changes in the equilibrium distribution of borrowing levels $\left\{D_{i}\right\}$ across types. This also implies that a social planner can only improve efficiency by changing the distribution of investment across types. Such a discount to the secondary market can be microfounded, e.g., by any transaction and legal costs; cost of immediacy (Grossman and Miller, 1988); market maker inventory cost (Ho and Stoll, 1981); or a profit required for outside buyers with alternative investment opportunities to hold idle cash (Allen and Gale, 1994; Choi et al., 2016). ${ }^{14}$ In Appendix C, we provide a microfoundation for the secondary market based on liquidity provision by short-termist outsiders.

Monetary policy: In addition to the lenders' initial endowment of funds $E$, the central bank provides liquidity $L$ to the market for loanable funds at $t=0$. The equilibrium riskfree rate $r$ then equates aggregate loan supply, consisting of the public supply $L$ and the private supply $E$ from lenders, with aggregate loan demand from borrowers:

$$
E+L=D_{h}+D_{\ell}
$$

\footnotetext{
${ }^{13}$ Bolton et al. (2011) and Malherbe (2014) build models where liquidity demand can be met with cash (inside liquidity) or sales of assets (outside liquidity), and asset sales feature asymmetric information about asset quality. For evidence on asset opacity, especially in case of financial intermediation, see, e.g., Morgan (2002), Hirtle (2006) and Flannery et al. (2013).

${ }^{14}$ See Section 6.3 for an extension that explicitly models a discount due to such cash-in-the-market pricing where buyers require a gross return $1 / \delta$.
} 
We identify monetary policy as changes in the central bank's supply of loanable funds $L$. In this setup, the central bank can effectively create loanable funds at $t=0$ which are then invested by borrowers and produce output at $t=2 .{ }^{15}$

An increase in $L$ can be interpreted as an injection of more central bank "money" in a model with perfect price stickiness. In this case, the amount of available money limits total investment in the economy, and the central bank is able to increase aggregate investment by increasing the money supply. We can apply a similar argument when interpreting changes in $L$ as changes in central bank reserves, which affect aggregate lending. ${ }^{16}$ Although our focus is on monetary policy that affects the supply of money or loanable funds, any inflows of liquidity into the economy can generate the same effect, e.g., international capital flows. ${ }^{17}$ However, our policy intervention is clearly different from fiscal policy where stimulus has a crowding-out effect that increases the interest rate rather than decreasing it.

Furthermore, examining changes in $L$ is equivalent to examining changes in the central bank target rate $r$ since there is a one-to-one equilibrium correspondence between $L$ and $r .{ }^{18}$ In our model, an advantage of analyzing changes in $L$ is that we can directly compare the equilibrium allocation with inefficient transmission to the first-best allocation where all funds are invested by the high type.

Similar to Allen et al. (2014) and Keister (2016), we assume that monetary stimulus at $t=0$ has costs at $t=2$ given by a function $c(L)$ which is increasing in $L$ to ensure that monetary policy is not a "free lunch." Although not explicitly modeled in this paper, these costs can be interpreted as, e.g., welfare losses from nominal price distortions.

Definition of equilibrium: The equilibrium of our economy is characterized by private decision variables $\left(b_{h}, b_{\ell}\right)$ or, equivalently, $\left(D_{h}, D_{\ell}\right)$, and price variables $(r, P)$ satisfying the following conditions:

1. Borrowers $i=h, \ell$ choose optimal leverage $b_{i}(r, P)$ taking prices $r$ and $P$ as given.

\footnotetext{
${ }^{15}$ In Section 6.1, we discuss the possibility of central bank intervention at $t=1$.

${ }^{16}$ Kashyap and Stein (1995) show that this is consistent with the effect of monetary policy on bank balance sheets. See Bernanke and Blinder (1992) and Bianchi and Bigio (2014) for general equilibrium models in which the central bank uses reserves to implement monetary policy. Our simplified setup would be a case with $100 \%$ reserve requirements in which total reserves equal total lending.

${ }^{17}$ See Bruno and Shin (2015) on the role of the international banking system in global capital flows, and Justiniano et al. (2015) on the foreign capital inflows and the housing boom.

${ }^{18}$ See Svensson (2003) for a discussion on the interchangeability between interest rates and money in NewKeynesian models.
} 
2. The risk-free rate $r$ clears the market for loanable funds:

$$
E+L=D_{h}+D_{\ell}
$$

3. The secondary market price $P$ satisfies the pricing rule given the private decision variables $\left(b_{h}, b_{\ell}\right)$ such that $P=\delta \times Q$ where $Q$ is defined by (2).

\section{Individual agent behavior}

We first analyze the optimizing behavior of individual agents taking prices $r$ and $P$ as given. Our analysis specifically focuses on how different types change their $t=0$ leverage-and therefore investment levels-differently in response to changes in these prices. We first show that high types react less elastically to changes in the interest rate $r$. We then show that high types can react more elastically to changes in the liquidation value $P$.

Since the lenders don't have access to the investment technology, they will lend their entire endowment. Borrowers choose how much to borrow, taking the prices $P$ and $r$ as given. Since all agents are risk neutral and the loanable funds market is competitive with no agency problem, the equilibrium market clearing rate $r$ is the expected rate of return for lending and the expected cost of borrowing, common across all agents in the economy. Intuitively, a borrower's expected payoff is therefore the total expected payoff from the investment minus the expected funding cost. Formally, we have the following result.

Lemma 1. When every borrower promises to pay a type-specific interest rate $r_{i}$ such that all lenders receive the risk free rate $r$ in expectation, we can write a type-i borrower's ex-ante expected payoff as

$$
\alpha(b) P(D+e)+(1-\alpha(b)) R_{i}(D+e)-(1+r) D .
$$

All proofs are relegated to Appendix A. When a borrower of type $i$ chooses her debt level $D$ resulting in leverage $b$, she ex-ante anticipates a liquidity shock at $t=1$ with probability $\alpha(b)$, leaving only $P$ per unit of investment, whereas she expects to collect $R_{i}$ per unit of investment when she does not experience a liquidity shock. Since $R_{\ell}>1+r$, both types borrow and invest in their projects. Note that we can also write the expected payoff (3) as follows:

$$
\underbrace{R_{i}(D+e)}_{\text {gross payoff }}-\underbrace{(1+r) D}_{\text {cost of funding }}-\underbrace{\alpha(b)\left(R_{i}-P\right)(D+e)}_{\text {cost of liquidity risk }}
$$


This illustrates that the liquidity risk effectively imposes an additional cost which is deducted from the gross investment return just like the cost of funding. The cost of liquidity risk can be decomposed into the loss per unit of assets liquidated, $R_{i}-P$, and the expected scale of liquidation, $\alpha(D)(D+e)$. We can factor out $e$ in the payoff (4) and arrive at an objective function with leverage $b$ as the choice variable: ${ }^{19}$

$$
e \times\left[R_{i} b-(1+r)(b-1)-\alpha(b)\left(R_{i}-P\right) b\right]
$$

Differentiating with respect to $b$, we get the first order condition characterizing borrower $i$ 's optimal leverage $b_{i}$ and, in turn, their loan demand $D_{i}::^{20}$

$$
\underbrace{R_{i}-(1+r)}_{\text {marginal excess return }}=\underbrace{\left(\alpha^{\prime}\left(b_{i}\right) b_{i}+\alpha\left(b_{i}\right)\right)\left(R_{i}-P\right)}_{\text {marginal cost of liquidity risk }}
$$

Without the liquidity risk, an agent should keep on increasing her investment as long as the marginal excess return - the wedge between the marginal product of investment $R_{i}$ and the marginal funding cost $1+r$-is positive. However, liquidity risk increases as leverage goes up, making additional borrowing more costly. At the optimal leverage, each type's wedge is filled with the type-specific cost of liquidity risk. The wedge is larger for the high types, and thus they can take more liquidity risk by building up higher leverage. ${ }^{21}$

Proposition 1. For given $r$ and $P$, high types choose higher leverage than low types, $b_{h}>b_{\ell}$.

Because in our model liquidity risk is the only risk for a borrower, high types' levering up more makes them riskier borrowers. This may seem counterintuitive if high types are thought of as "good borrowers" who should be "safe borrowers." However, in our model, type corresponds to investment productivity only, which induces more productive types to endogenously take on higher liquidity risk. ${ }^{22}$

\subsection{Response to interest rate}

We now analyze how borrowers respond to changes in the interest rate. The wedge between the marginal product of investment $R_{i}$ and the marginal funding cost $1+r$ becomes

\footnotetext{
${ }^{19}$ Appendix D studies the general problem with choosing both equity and leverage.

${ }^{20}$ The second order condition $-\left(\alpha^{\prime \prime}\left(b_{i}\right) b_{i}+2 \alpha^{\prime}\left(b_{i}\right)\right)\left(R_{i}-P\right)<0$ is satisfied since $\alpha^{\prime \prime}(b)>0$.

${ }^{21}$ Note that the marginal funding cost is equal to $1+r$ for all agents with the binding first order condition, and thus there is no external finance premium that could be different across types, unlike in the conventional credit channel models.

${ }^{22}$ We consider type-specific liquidity risk in Section 6.2 and show that our results go through.
} 


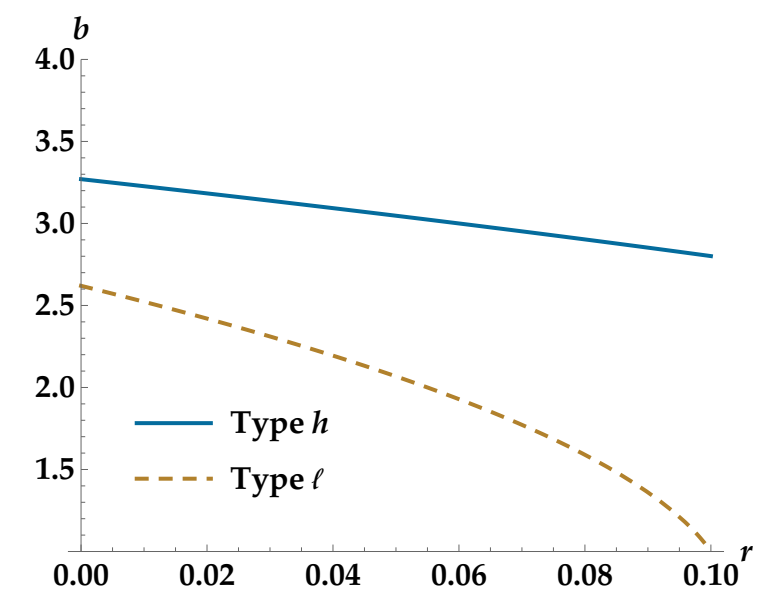

Figure 2: Optimal leverage $b_{i}$ as a function of the interest rate $r$ for the two types $h$ and $\ell$ (partial equilibrium). The functional forms and parameter values used are the same as in Section 5 with $\alpha(b)=0.03(b-1)^{2}$ and $P=0.8$.

larger when the interest rate is lower, so that borrowers have more "room" to take additional liquidity risk when the funding cost is lower.

Proposition 2. For a reduction in $r$, all borrowers increase their leverage, i.e. $\partial b_{i} / \partial r<0$ for $i=h, \ell$. High types respond less than low types, i.e. $\left|\partial b_{h} / \partial r\right|<\left|\partial b_{\ell} / \partial r\right|$.

Figure 2 illustrates the optimal leverage $b_{i}$ for each type $i$ for different levels of $r$. The intuition for the heterogeneous response can be seen from the first-order condition (5) where a drop in $r$ leads to an identical increase in the marginal excess return on the LHS for both types which has to be balanced by an increase in the marginal cost of liquidity risk on the RHS. To achieve this, high types require a smaller increase in leverage than low types for two reasons:

1. Since high types are more levered than low types and the expected scale of liquidation $e \times(\alpha(b) b)$ is convex in $b$, high types' exposure to liquidity risk is more sensitive to changes in leverage than low types':

$$
\alpha^{\prime}\left(b_{h}\right) b_{h}+\alpha\left(b_{h}\right)>\alpha^{\prime}\left(b_{\ell}\right) b_{\ell}+\alpha\left(b_{\ell}\right)
$$

2. High types suffer a bigger loss per dollar of assets when forced into liquidation:

$$
R_{h}-P>R_{\ell}-P
$$

These two reasons both imply that the marginal cost of liquidity risk in the first order 


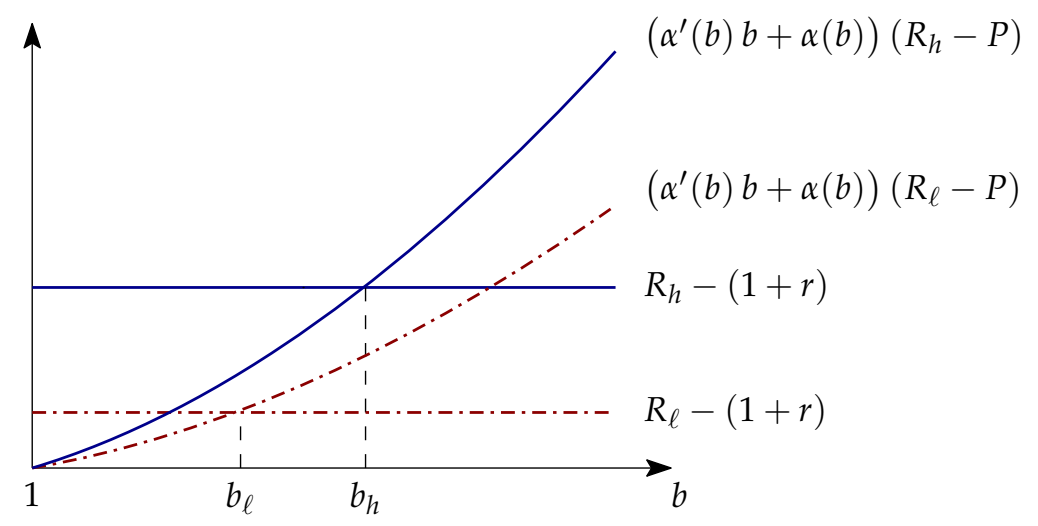

Figure 3: Marginal excess return and cost of liquidity risk for both types.

condition (5) is more sensitive to changes in leverage for high types. Figure 3 illustrates the different sensitivities by plotting marginal excess return and marginal cost of liquidity risk for the two types. Since the marginal cost of liquidity risk is steeper for high types, the same parallel shift in the marginal excess return leads to a smaller response in high types' leverage. ${ }^{23}$

\subsection{Response to secondary market price}

We next analyze how borrowers respond to the changes in the secondary market price $P$. An increase in $P$ makes liquidation less costly and therefore reduces the marginal cost of liquidity risk on the RHS of the first order condition (5). Similar to a drop in the interest rate $r$, this leads both types to lever up. However, while high types respond less to changes in $r$ than low types, they may respond more to changes in $P$ than low types.

In contrast to $r$, which enters the first-order condition (5) of both types with a factor of -1 , the liquidation value $P$ enters with a factor of $\left(\alpha^{\prime}\left(b_{i}\right) b_{i}+\alpha\left(b_{i}\right)\right)$, which is larger for high types. Therefore, while a drop in $r$ generates the same slack in the first-order condition for all types, an increase in $P$ generates more slack for high types than for low types. This effect on its own would imply that high types respond more to changes in $P$ than low types. However, since high types are more levered and therefore exposed to more liquidity risk as discussed in Section 3.1 they need smaller increases in leverage to achieve the same degree of tightening of their first-order condition.

With these competing effects, we have the following result.

\footnotetext{
${ }^{23}$ Contrary to the second-order effect that a change in the choice variable has on the maximized objective function (envelope theorem), we are dealing with the first-order effect that a change in a price variable has on the choice variable.
} 


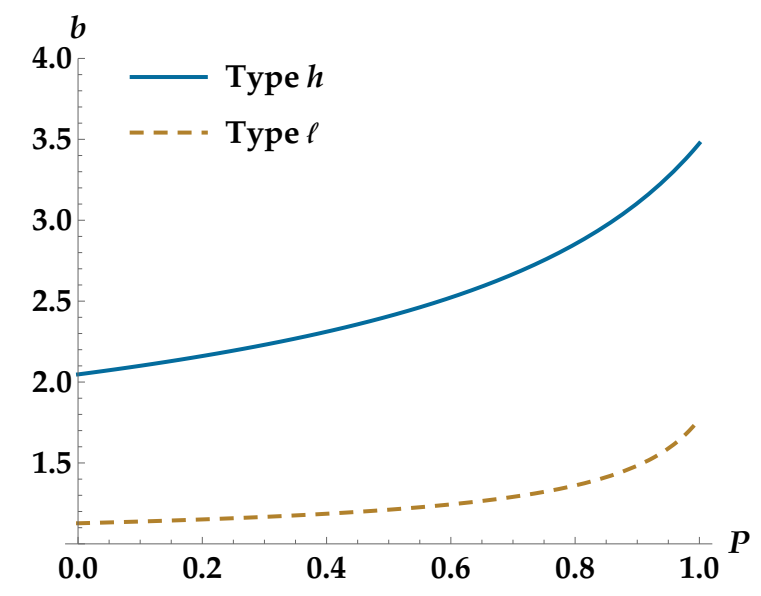

Figure 4: Optimal leverage $b_{i}$ as a function of the liquidation value $P$ for the two types $h$ and $\ell$ (partial equilibrium). The functional forms and parameter values used are the same as in Section 5 with $\alpha(b)=0.03(b-1)^{2}$ and $r=0.09$.

Proposition 3. For an increase in $P$, all borrowers increase their leverage, i.e. $\partial b_{i} / \partial P>0$ for $i=h, \ell$. High types respond more than low types to a change in $P$, i.e. $\partial b_{h} / \partial P>\partial b_{\ell} / \partial P$, if and only if

$$
\frac{\alpha^{\prime \prime}\left(b_{h}\right) b_{h}+2 \alpha^{\prime}\left(b_{h}\right)}{\alpha^{\prime \prime}\left(b_{\ell}\right) b_{\ell}+2 \alpha^{\prime}\left(b_{\ell}\right)}<\frac{\left(R_{h}-(1+r)\right) /\left(R_{h}-P\right)^{2}}{\left(R_{\ell}-(1+r)\right) /\left(R_{\ell}-P\right)^{2}} .
$$

Condition (6) captures the two competing effects of $P$ on the first order condition (5) and can hold locally or globally, depending on the parameters chosen. For example, Figure 4 illustrates the optimal leverage $b_{i}$ as a function of $P$ for quadratic liquidity risk $\alpha(b)=a(b-1)^{2}$ and shows high types responding more than low types at every level of $P$.

\section{Monetary policy with heterogeneous risk taking}

We are interested in the effect of monetary policy in the initial period $t=0$ on aggregate output in the final period $t=2$. Since borrowers in our model are heterogeneous in their investment productivity, changes in aggregate output also depend on how the distribution of initial investment across different types changes. Therefore we have two channels of monetary policy transmission: Monetary policy-a change in L-affects aggregate output (i) through its effect on the quantity of aggregate investment-a change in I-and (ii) through its effect on the average quality of investment-a change in $q$.

Recall that we assume no output is lost through the secondary market liquidation process in the interim period $t=1$. Aggregate output in the final period $t=2$ can therefore 
be written as the average quality of investment times the aggregate amount invested:

$$
\begin{aligned}
Y & =R_{h}\left(D_{h}+e\right)+R_{\ell}\left(D_{\ell}+e\right) \\
& =q \times I,
\end{aligned}
$$

where $q$ is the average productivity of investment defined in (1). Denoting output net of the costs of monetary policy by $\bar{Y}=Y-c(L)$, the effect of monetary policy in the form of changes in central bank liquidity $L$ can then be decomposed into three parts:

$$
\frac{d \bar{Y}}{d L}=\underbrace{q \times \frac{d I}{d L}}_{\text {new investment }}+\underbrace{\frac{d q}{d L} \times I}_{\text {change in quality }}-\underbrace{c^{\prime}(L)}_{\text {marginal cost }}
$$

The first and third parts are straightforward and standard. In our model, total investment equals total available funds, $I=L+E+2 e$, so investment changes one-for-one with monetary policy, $d I / d L=1 .{ }^{24}$ Our focus is therefore on the second part, how monetary policy affects the average quality of investment. While the effect on aggregate investment is always positive, the effect on average quality can be negative, dampening the effectiveness of monetary policy. If quality deteriorates sufficiently, it may even reverse the effect of monetary stimulus on output such that $d \bar{Y} / d L<0$.

We can decompose the effect of $L$ on quality as follows:

$$
\frac{d q}{d L}=\underbrace{\frac{d q}{d r}}_{\text {'quality elasticity' }} \times \underbrace{\frac{d r}{d L}}_{\text {'stimulus pass-through' }}
$$

Monetary policy affects the average quality of investment through its effect on the equilibrium risk-free rate which, in turn, affects average quality. If the first factor in the decomposition (7), which we refer to as 'quality elasticity,' is positive and the second factor, which we refer to as 'stimulus pass-through', is negative, monetary stimulus decreases the interest rate but at the same time lowers the quality of investment. Digging deeper into these two parts highlights the effects of our model and the mechanism of negative feedback between the two factors, (i) a deterioration in investment quality in response to a lower interest rate, and (ii) a decrease in aggregate loan demand in response to the quality

\footnotetext{
${ }^{24}$ The statement $d I / d L=1$ requires the market for loanable funds to clear for arbitrarily high levels of $L$, i.e. the risk free rate $r$ has to be unconstrained. However, our assumption that $P<1+r$ with $P=\delta \times Q>0$ effectively implies a lower bound on the risk free rate, $r>-1$. As a result, we don't have any hoarding of liquidity which would reduce investment, e.g., as in Diamond and Rajan (2011) or Gale and Yorulmazer (2013). See Choi et al. (2016) for an analysis that allows for hoarding, such that an increase in $L$ at $t=0$ does not necessarily lead to the same increase in $I$.
} 
deterioration, leading to a further decrease in the interest rate.

First, consider the quality elasticity, i.e. the effect of the risk-free rate $r$ on the average quality of investment $q$. Recall from equation (1) that average quality $q$ is determined by the distribution of borrowing $D_{h}$ and $D_{\ell}$ or, equivalently, of leverage $b_{h}$ and $b_{\ell}$. The optimal leverage, in turn, depends on the risk-free rate $r$ as well as the secondary-market price $P$. When the secondary market price is an endogenous variable, we can further decompose the quality elasticity into a direct and an indirect effect:

$$
\frac{d q}{d r}=\underbrace{\frac{\partial q}{\partial r}}_{\text {direct effect }}+\underbrace{\frac{\partial q}{\partial P} \times \frac{d P}{d r}}_{\text {indirect effect }}
$$

Next, consider the stimulus pass-through, i.e. the effect of a liquidity injection $L$ on the interest rate $r$. Note that the market clearing condition equating supply and demand of loanable funds is given by

$$
L+E=D_{h}+D_{\ell}
$$

Implicit differentiation yields the equilibrium stimulus pass-through as the inverse of the effect of $r$ on the aggregate demand for loanable funds:

$$
\frac{d r}{d L}=\left(\frac{d}{d r}\left(D_{h}+D_{\ell}\right)\right)^{-1}=\frac{1}{e}\left(\frac{d b_{h}}{d r}+\frac{d b_{\ell}}{d r}\right)^{-1}
$$

When additional funds are injected, the market clearing interest rate drops more if aggregate loan demand is less elastic. Given the dependence of optimal leverage $b_{i}$ on the risk-free rate $r$ and the price $P$, the change in leverage also goes through two channels:

$$
\frac{d b_{i}}{d r}=\underbrace{\frac{\partial b_{i}}{\partial r}}_{\text {direct effect }}+\underbrace{\frac{\partial b_{i}}{\partial P} \times \frac{d P}{d r}}_{\text {indirect effect }}
$$

\subsection{Direct effects of monetary stimulus}

First, we analyze the direct effect of a change in liquidity $L$, assuming, for now, that the price $P$ in the secondary market is fixed so that $d P / d r=0$. We show that even in the absence of any price effects, our model generates a dampening effect on monetary stimulus because of the heterogeneous response of different types to changes in the interest rate.

Consider first the stimulus pass-through in equations (9) and (10). Without a change in $P$, the shift in the supply of loanable funds leads to a move along the demand for funds which is decreasing in the interest rate, $\partial b_{i} / \partial r<0 \Rightarrow \partial D_{i} / \partial r<0$ (Proposition 2). The 
market clearing rate therefore drops in response to an injection of loanable funds:

$$
\frac{d r}{d L}=\left(\frac{\partial}{\partial r}\left(D_{h}+D_{\ell}\right)\right)^{-1}=\frac{1}{e}\left(\frac{\partial b_{h}}{\partial r}+\frac{\partial b_{\ell}}{\partial r}\right)^{-1}<0 \text { for } \frac{d P}{d r}=0
$$

Consider next the quality elasticity in equation (8). Without a change in $P$, we have:

$$
\frac{d q}{d r}=\frac{\partial q}{\partial r} \text { for } \frac{d P}{d r}=0
$$

Using the definition of $q$, we can write this as follows:

$$
\frac{\partial q}{\partial r}=-\frac{\sum_{i}\left(\left(q-R_{i}\right) \times \partial b_{i} / \partial r\right)}{\sum_{i} b_{i}}
$$

Intuitively, for a lower interest rate, average quality should decrease (increase) if $b_{i}$ increases more for the low (high) type. Formally, note the two factors in the summation in the numerator of (12): The first factor, $q-R_{i}$, is positive for the low type and negative for the high type and, since $q$ is biased upward with $b_{h}>b_{\ell}$, summation only over $q-R_{i}$ would yield a positive result. The second factor, $\partial b_{i} / \partial r$, the direct effect of the risk-free rate $r$ on the leverage $b_{i}$ of type $i$ is negative; this factor plays the role of a weighting of different types, determining whether the positive or the negative part of $q-R_{i}$ dominates. The weighting and ultimately the sign of $\partial q / \partial r$ therefore depends on differences in sensitivity across types. Since Proposition 2 shows that $\left|\partial b_{h} / \partial r\right|<\left|\partial b_{\ell} / \partial r\right|$, i.e. high types are less sensitive to interest rate changes, we have that $\partial q / \partial r$ is positive. Therefore, overall investment quality deteriorates when the interest rate decreases.

Corollary 1. Without changes in $P$, monetary stimulus leads to a decline in the interest rate, i.e. $d r / d L<0$, which leads to a deterioration in investment quality, i.e. $d q / d r>0$. The overall effect is a dampening of monetary policy transmission:

$$
\frac{d q}{d L}=\frac{d q}{d r} \times \frac{d r}{d L}<0 \quad \text { for } \quad \frac{d P}{d r}=0
$$

Hence, while monetary loosening leads to an increase in investment, it also leads to a deterioration of the quality of investments. This, in turn, dampens the effect of monetary stimulus. The effect is illustrated in Figure 1 through the blue arrows.

Note that we have a constant returns to scale investment technology so that, without any frictions, there would be no lack of good investment opportunities in our model. Hence, the dampening effect of stimulus comes from the heterogeneous responses of agents 
and the change in the composition of investment.

\subsection{Feedback through liquidation values}

We now account for the endogeneity of the liquidation value $P$ and examine how changes in the equilibrium value of $P$ can strengthen the impairment of monetary transmission. Recall that we include the indirect effects through the secondary market price $P$ in the quality elasticity (8) as well as in the stimulus pass-through (10). The direction of the indirect effects is determined by three derivatives:

1. $d P / d r$ : the equilibrium comovement between the liquidation value $P$ and the interest rate $r$

2. $\partial b_{i} / \partial P$ : the effect of the liquidation value on the leverage of type $i$

3. $\partial q / \partial P$ : the direct effect of the liquidation value on the average quality of investment

We are interested in determining when the indirect effects further dampen the transmission of monetary policy. In particular, when a drop in the equilibrium interest rate $r$ coincides with a drop in the equilibrium liquidation value $P$, that is, $d P / d r>0$. This appears in both the quality elasticity and the stimulus pass-through and is necessary for the feedback effects. Recall that we assume buyers in the secondary market in $t=1$ cannot observe individual quality but know the average quality $Q$ of assets sold, and the secondary market price therefore reflects this average quality such that $P=\delta \times Q$. The average quality $Q$ of assets being sold in the secondary market (defined in equation (2)) is a function of each type's optimal leverage $b_{i}$, and thus depends on the risk-free rate $r$ as well as the liquidation value $P$. The equilibrium liquidation value is therefore implicitly defined by the fixed-point condition

$$
P=\delta \times Q(r, P)
$$

Given this implicit definition of $P$ in (13), the equilibrium effect of $r$ on $P$ is given by

$$
\frac{d P}{d r}=\frac{\delta \times \partial Q / \partial r}{1-\delta \times \partial Q / \partial P}
$$

Sufficient conditions for $d P / d r>0$ are therefore $\partial Q / \partial r>0$, that is, the average quality of liquidated assets has to decrease after a drop in the interest rate, and $\partial Q / \partial P<1 / \delta$ to guarantee a stable fixed point. ${ }^{25}$

\footnotetext{
${ }^{25}$ There is an important difference between average quality of all assets $q$ and average quality of liquidated assets $Q$. Since high types are more levered, they are more likely to face liquidation, $\alpha\left(b_{h}\right)>\alpha\left(b_{\ell}\right)$, so
} 


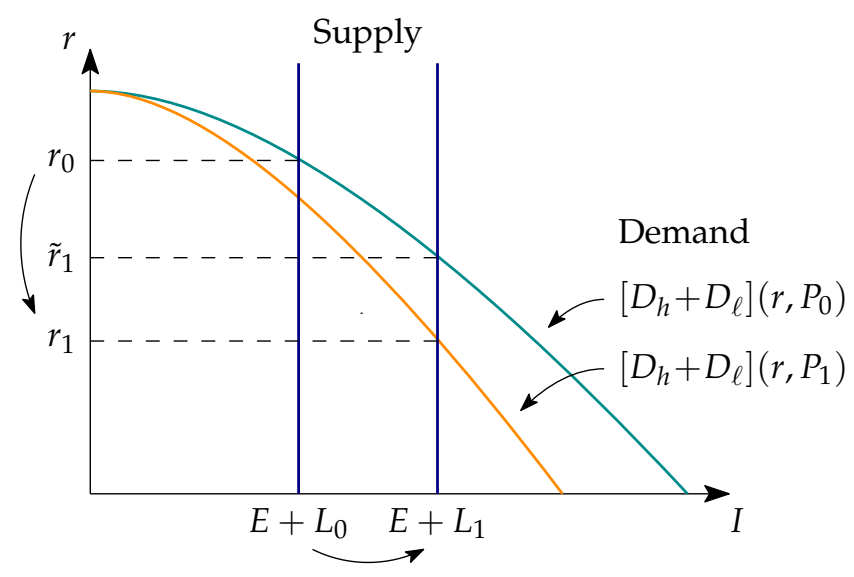

Figure 5: Stimulus pass-through for an increase in liquidity from $L_{0}$ to $L_{1}$. The direct effect is along the original demand curve from $r_{0}$ to $\tilde{r}_{1}$; the indirect effect is from $\tilde{r}_{1}$ to $r_{1}$ due to a shift in the demand curve as $P$ drops from $P_{0}$ to $P_{1}$.

For stimulus pass-through, the indirect effect works by changing the responsiveness of borrowing demand $D_{i}$, driven by the responsiveness of leverage $b_{i}$, to the interest rate $r$ and is illustrated in Figure 5. If the indirect effect in (10) is positive, it renders borrowing demand less responsive to $r$, which implies a stronger stimulus pass-through-a larger drop in $r$ following an increase in $L$. Since the liquidation value $P$ captures (inversely) how costly a liquidity shock is, agents lever less for a lower liquidation value, $\partial b_{i} / \partial P>0$, as shown in Proposition 3. With $d P / d r>0$, the indirect effect through $P$ offsets the direct effect and strengthens the stimulus pass-through, i.e. $d r / d L$ becomes more negative.

For quality elasticity, heterogeneous responses to the change in $P$ can strengthen the effect as illustrated in Figure 6. If the indirect effect is positive, it means that quality of investment deteriorates further due to the heterogenous response of different types to changes in $P$ (orange arrow in Figure 1). For $d P / d r>0$, the sign of the indirect effect depends on $\partial q / \partial P$. As in the case of the direct effect of the risk-free rate on quality, $\partial q / \partial r$ in (12), the difference in sensitivity across types is key: average quality decreases if high types reduce their leverage more than low types in response to a lower liquidation price.

Note that these heterogeneous responses to $P$ can also impair the stimulus effect by directly depressing the liquidation value itself. Average quality of the liquidated assets decreases if high types reduce their leverage more than low types in response to a lower liquidation price, i.e. $\partial Q / \partial P>0$, which leads to greater $d P / d r$ as in (14). This affects both stimulus pass-through and quality elasticity, amplifying the feedback.

their assets are over-represented in the secondary market, $Q>q$. While average quality of all assets always declines in response to a drop in the interest rate, $\partial q / \partial r>0$ (Corollary (1)), we need an additional condition to guarantee $\partial Q / \partial r>0$. 


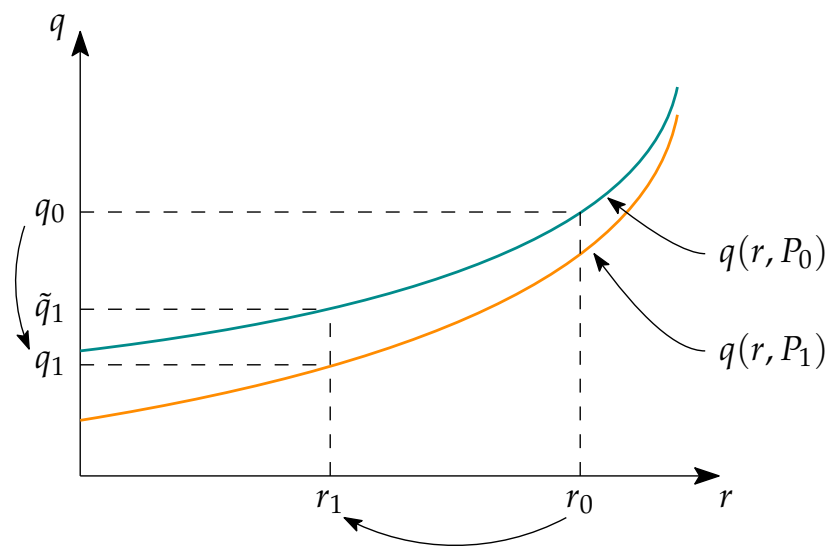

Figure 6: Quality elasticity for a drop in the interest rate from $r_{0}$ to $r_{1}$. The direct effect is along the original quality curve from $q_{0}$ to $\tilde{q}_{1}$; the indirect effect is from $\tilde{q}_{1}$ to $q_{1}$ due to a shift in the quality curve as $P$ drops from $P_{0}$ to $P_{1}$.

Corollary 2. The conditions for amplifying indirect effects are:

$$
\begin{gathered}
\partial Q / \partial r>0 \\
\partial Q / \partial P<1 / \delta \\
\partial q / \partial P>0 \\
\partial Q / \partial P>0
\end{gathered}
$$

We have the following:

1. Conditions (15) and (16) are sufficient for feedback in stimulus pass-through.

2. Conditions (15), (16) and (17) are sufficient for feedback in quality elasticity.

3. Under condition (18), there is a feedback in P itself, strengthening the feedbacks through both stimulus pass-through and quality elasticity.

4. The four conditions are not mutually exclusive.

In sum, combining the effects of $r$ and $P$ on average quality $q$ we see that our model can generate a strong spiral illustrated by Figure 7. Injections of liquidity increase the supply of loanable funds which puts downward pressure on the interest rate. Any reduction in the interest rate leads worse borrowers to lever up relatively more than higher quality borrowers, directly leading to a deterioration in the average quality of investment. In addition, under mild conditions, the expected quality of assets sold in the secondary market at $t=1$ also deteriorates. This, in turn, leads to a decrease in the liquidation value which 


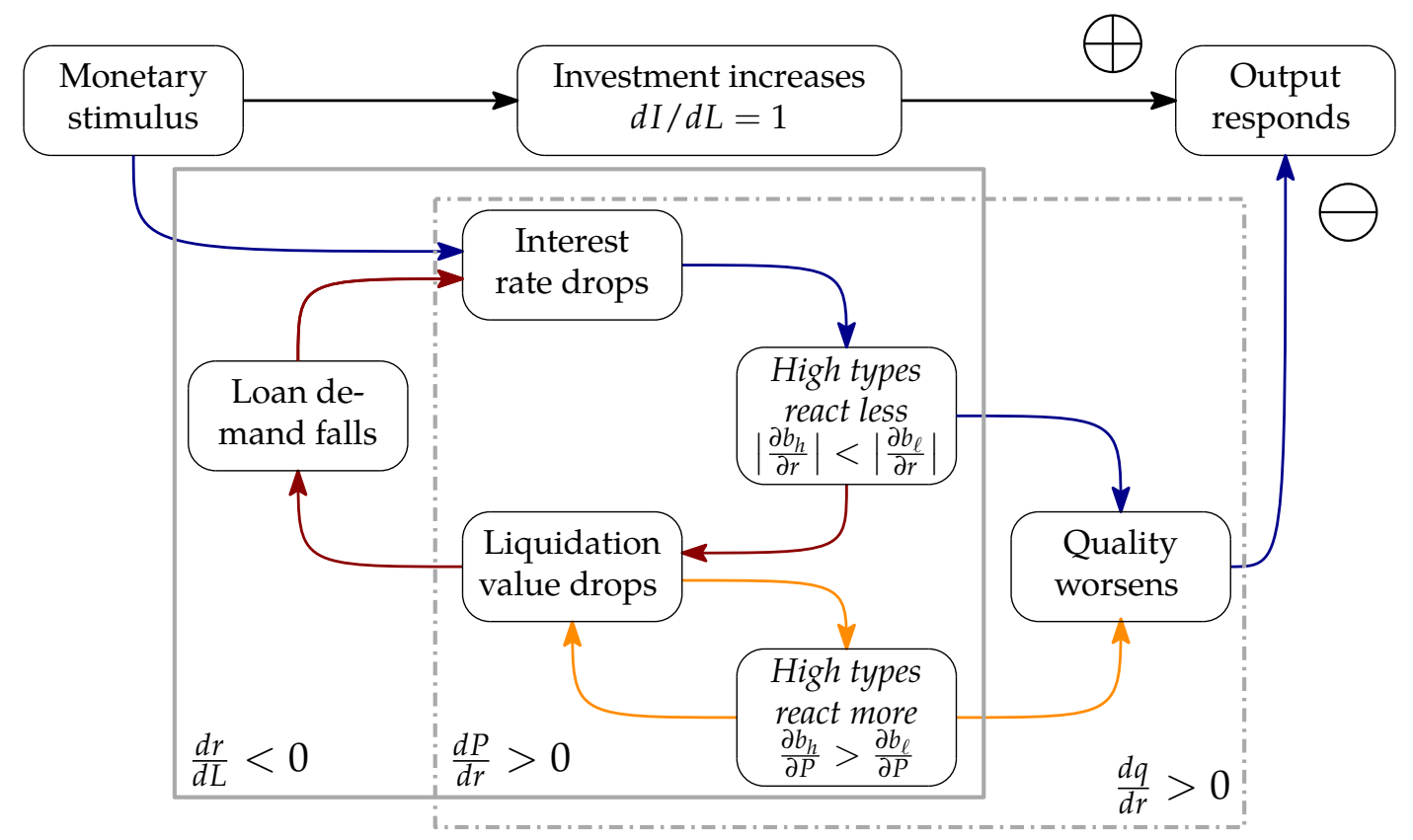

Figure 7: Summary of negative feedback spirals dampening the effect of monetary policy

reduces borrowers' demand for funds, causing further downward pressure on the interest rate. Finally, if better borrowers react more to the decrease in the liquidation value, (i) average quality deteriorates also indirectly (through $P$ ), and (ii) the liquidation value itself becomes more depressed, which strengthens the spiral further. The overall effect of the liquidity injection is then a large drop in the interest rate but only a small increase or potentially even a decrease in total output since total borrowing shifts from agents with high productivity to agents with low productivity.

This impairment in monetary transmission is purely driven by inefficient credit (re)allocation among heterogeneous agents-unlike in other macro models with financial intermediation. With the constant returns to scale investment technology, there is no lack of good investment opportunities; there are no agency problems in the intermediation process preventing an efficient allocation of funds; and forced liquidation by borrowers does not destroy resources. In sum, the dampening effect in our model is purely due to the heterogeneous responses of borrowers to equilibrium prices and the resulting changes in the composition of investment.

While our model does not specifically distinguish between monetary stimulus and tightening, the effects on transmission should not be thought of as symmetric for stimulus and tightening. Our mechanism critically depends on financial frictions, in particular endogenously increasing cost of liquidity risk and secondary market frictions. Both of these 
Table 1: Parameters of numerical example

\begin{tabular}{ll}
\hline Parameter & Description \\
\hline$E=1$ & Lender endowment \\
$e=0.5$ & Borrower equity \\
$\left(R_{h}, R_{\ell}\right)=(1.3,1.1)$ & Borrower expected returns \\
$a \in\{0,0.02,0.03\}$ & Liquidity risk parameter \\
$\left(\gamma_{1}, \gamma_{2}\right)=(1,0.5)$ & Cost parameters \\
$\delta=0.5$ & Liquidation discount \\
\hline
\end{tabular}

frictions are naturally more severe in downturns (in particular during a crisis) than in upturns. In our specific setup, the liquidity risk underlying the heterogeneous responses and therefore the dampened transmission of monetary policy is more relevant during downturns.

\section{Numerical example}

In this section we present a numerical example to illustrate the impaired transmission of monetary policy in our framework. We choose quadratic functions for the liquidity risk at $t=1$ and the cost of monetary policy at $t=2$ :

$$
\alpha(b)=a(b-1)^{2}, \quad c(L)=\gamma_{1} L+\gamma_{2} L^{2}
$$

For the parameters of the model we use the values in Table 1.

Figure 8 compares the effect of monetary policy in the first-best economy $(a=0)$ and in a second-best economy characterized by our frictions $(a=0.2)$. In the first-best economy without frictions, only the high type $h$ invests and any liquidity injected is allocated only to the high type. Starting from $L=0$, monetary stimulus at $t=0$ increases output at $t=2$ at a rate equal to the highest type's return, $R_{h}=1$.3. Since we assume that monetary policy at $t=0$ has $\operatorname{costs} c(L)$ at $t=2$, the stimulus effect is concave even in the first-best economy (blue solid line in Figure 8). In contrast, in the second-best economy with agents facing liquidity risk and lemons pricing, the effect of monetary policy is considerably impaired (red dashed line in Figure 8). Since it is no longer the case that only the high type invests, any stimulus is split across the high and low type, resulting in a flatter path starting at $L=0$. As stimulus increases, the quality deterioration effect kicks in and final output is strongly concave and eventually decreasing in $L$. 


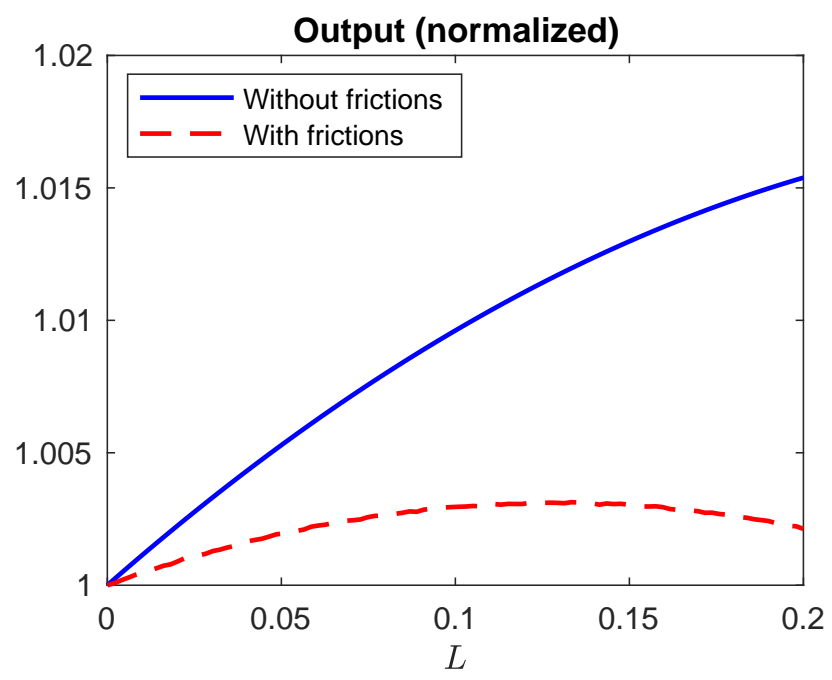

Figure 8: Effect of monetary policy on output with and without frictions
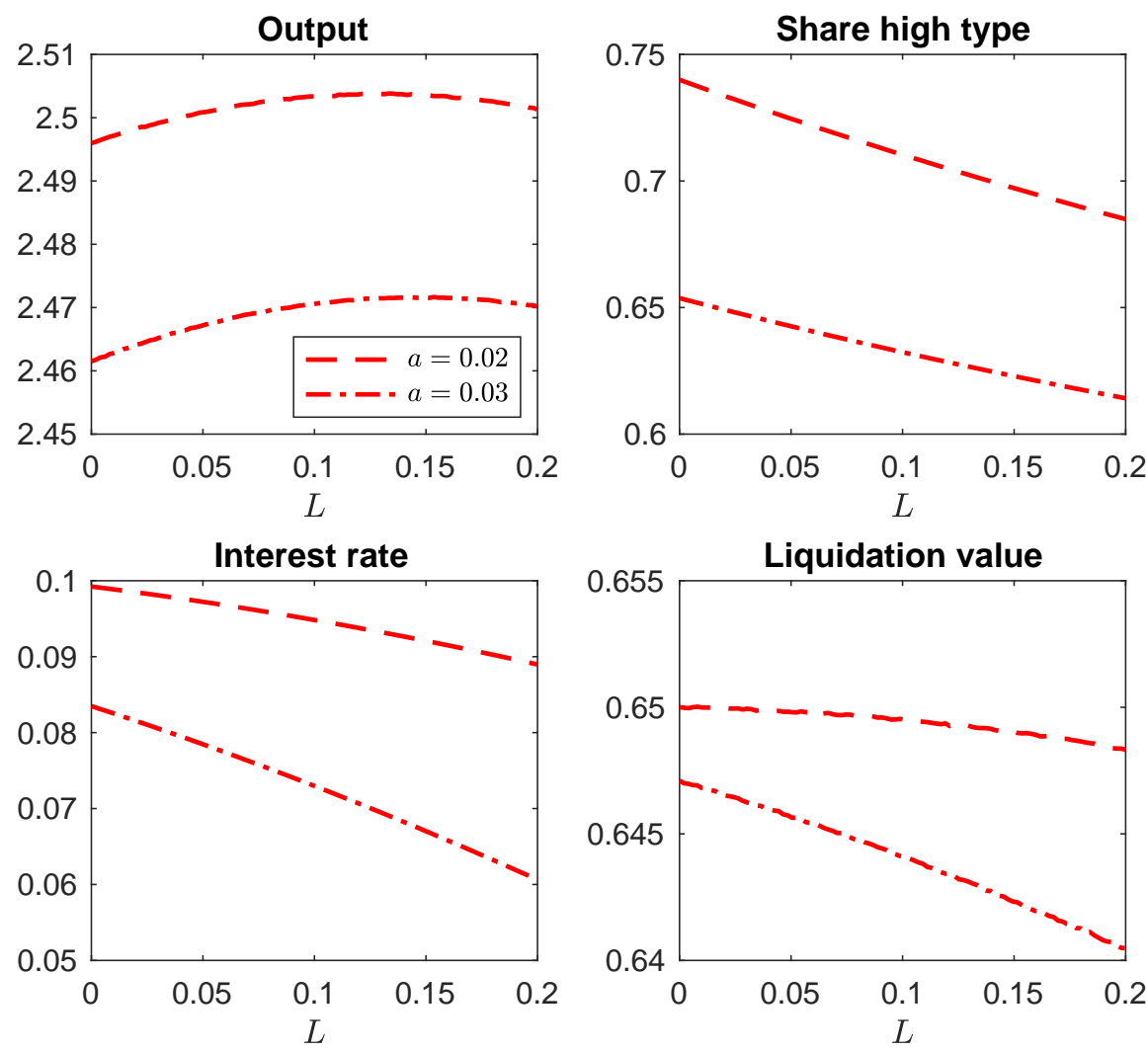

Figure 9: Effects of monetary policy under different severities of liquidity risk 
Figure 9 shows the effect of monetary policy under two scenarios that differ in the severity of the liquidity risk, $a \in\{0.02,0.03\}$. The first row shows final output $\bar{Y}$ and the share of the high type's investment $I_{h} /\left(I_{h}+I_{\ell}\right)$, while the second row shows the equilibrium interest rate $r$ and the lemons price $P$. The first thing to note is that more severe liquidity risk reduces the level of output overall. This is significant, since aggregate investment is always $I=2 e+E+L$ so the difference in output for a given level of $L$ is due only to the endogenous distribution of borrowing across types, as is clear from the top right panel. This is also reflected in the different levels of the interest rate $r$ and the liquidation value $P$. With higher liquidity risk $a$, overall borrowing demand is lower so the equilibrium interest rate is lower. This, however, leads worse types to invest which is reflected in the lower liquidation value (recall that $P=\delta Q$ ). Furthermore, we see that the effect of monetary policy is weaker in the scenario with more severe liquidity risk: output responds less and flattens earlier while the interest rate and liquidation value drop faster as stimulus increases.

\section{Extensions}

In this section, we discuss extensions of our baseline model as well as its critical assumptions.

\subsection{Secondary market intervention}

Our policy analysis so far has focused on monetary loosening at $t=0$, which can be strongly impaired by the feedback between liquidation values at $t=1$ and loan demand at $t=0$. Naturally, this feedback effect could be alleviated through an intervention in secondary markets to support liquidation values. If such a program for $t=1$ were announced or anticipated at $t=0$, it could counteract the credit misallocation at $t=0$.

One such program would be to announce a floor for the secondary market price, which would result in an exogenously fixed $P$. Such a policy would eliminate the indirect effects through changes in $P$, both for the quality elasticity as well as for the stimulus passthrough. However, this could be costly since the policy maker has to credibly commit to purchasing any amount of assets at that price. An alternative program would be to support private buyers with subsidies or loss-sharing arrangements. In our setup, this would correspond to a reduction in the discount $1-\delta$ between average quality and liquidation value. 
Comparing interest rate policy and secondary market intervention, we have the following result on their relative cross-sectional effects.

Corollary 3. Comparing the heterogeneous responses of the two policies, we have:

$$
\left|\frac{\partial b_{h} / \partial r}{\partial b_{\ell} / \partial r}\right|<\left|\frac{\partial b_{h} / \partial P}{\partial b_{\ell} / \partial P}\right|
$$

Thus, the response in leverage of high types relative to low types for a change in $P$ is larger than that for a change in $r$. Suppose that the central bank wishes to induce further investment by productive high types without affecting less productive low types to minimize efficiency losses. Corollary 3 implies that this goal can be achieved more effectively by raising $P$ than by lowering $r$ as liquidity provision in the secondary market directly affects liquidity risk, our primary source of financial frictions. See Choi et al. (2016) for more discussion on various policy measures as well as their timing.

Another benefit of this intervention is that it could generate a positive spiral that partially offsets the negative spiral discussed in the paper; higher $P$ increases aggregate loan demand and raises the interest rate, which leads to an improvement in overall investment quality through the heterogeneous responses and thus a further increase in $P$. If the policy maker implements monetary stimulus and simultaneously announces these programs, the impairment effect could be alleviated.

A similar effect would arise if we incorporated a further indirect effect of monetary policy at $t=0$ through an inter-temporal no-arbitrage condition linking $P$ and $r$. For example, with cash-in-the-market pricing as in Section 6.3, we could explicitly model the $t=0$ portfolio decision of outside investors between investing until $t=2$ and earning the risk free rate $1+r$ or keeping "dry powder" to buy assets at $t=1$ and earning $R_{i} / P_{i}$. We analyze such a no-arbitrage condition in Choi et al. (2016).

\subsection{Type-specific liquidity risk}

For simplicity, we used the same $\alpha$ for liquidity risk for both types $i=h, \ell$ so far. Suppose that instead we allow for type-specific liquidity risk with $\alpha_{h}(b)<\alpha_{\ell}(b)$ and $\alpha_{h}^{\prime}(b)<\alpha_{\ell}^{\prime}(b)$; compared to low types, high types then have lower liquidity risk for given leverage $b$ and their liquidity risk increases more slowly.

In that case, the first order condition (5) becomes

$$
\underbrace{R_{i}-(1+r)}_{\text {marginal excess return }}=\underbrace{\left(\alpha_{i}^{\prime}\left(b_{i}\right) b_{i}+\alpha_{i}\left(b_{i}\right)\right)\left(R_{i}-P\right)}_{\text {marginal expected liquidity cost }} .
$$


Now, the wedge $R_{i}-(1+r)$, which is larger for the high types, will be filled with typespecific liquidity risk. Note that in this case the high types' liquidity risk is lower and flatter than the liquidity risk for low types for the same level of leverage $b$. Hence, in this case, high types can afford to increase leverage even more compared to the low types so that the difference between the optimal levels of borrowing between the high and the low types will be greater.

We show in Appendix B.2 that our results are robust to allowing for type-specific liquidity risk. In particular, we show that high types respond less than low types to changes in the interest rate $r$ (as in Proposition 2), that high types can respond more than low types to changes in the price $P$ (as in Proposition 3), and that these heterogeneous responses result in spirals and the dampening effects (as in Corollary 1 and 2). The intuition for the results remains the same. What matters is that high types have a bigger wedge $R_{i}-(1+r)$ and thus can afford to increase leverage more, and while changes in the interest rate create the same slack in the first-oder condition and therefore benefit low types more, changes in the price can benefit high types more.

\subsection{Type-specific liquidation values}

We now analyze an alternative case to illustrate how the dampening mechanism due to heterogeneous responses can arise even without the lemons pricing assumption. Similar to the framework in Choi et al. (2016), we drop the assumption of incomplete information in the secondary market and examine instead a case where buyers can distinguish seller types. To ensure that liquidation remains costly to the borrowers, liquidation values have to be below fundamental value, i.e. $P_{i}<R_{i}$. We therefore assume that secondary market liquidity is limited, leading to cash-in-the-market pricing. ${ }^{26}$ In this case, the increase in aggregate investment due to monetary stimulus leads to an increase in the discount in the secondary market, also resulting in an additional dampening effect on output through liquidation values. The only effect missing is the feedback between high types' response to liquidation values and liquidation values themselves.

Suppose that the amount of cash available to purchase assets at $t=1$ is limited to an

\footnotetext{
${ }^{26}$ Without a discount relative to fundamental value, there would be no cost associated with liquidity risk and borrowers' demand for funds would be perfectly elastic, i.e.

$$
D_{i}(r)= \begin{cases}\infty & \text { for } r<R_{i} \\ (0, \infty) & \text { for } r=R_{i} \\ 0 & \text { for } r>R_{i}\end{cases}
$$

Besides cash-in-the-market pricing, other assumptions leading to a discount could be used, e.g. risk aversion or alternative investment opportunities of the buyers.
} 
amount C, e.g., due to limited participation as in Allen and Gale $(1994,1998)$. As a result, when sufficiently large amounts of assets are sold in the secondary market, the asset prices suffer from a discount, which increases in the aggregate amount of assets liquidated.

Let $V$ denote the total fundamental value of assets being sold in the secondary market:

$$
V=\sum_{i} \alpha\left(b_{i}\right) R_{i}\left(D_{i}+e\right)=e \times \sum_{i} \alpha\left(b_{i}\right) R_{i} b_{i}
$$

When the cash available in the market is less than $V$, assets are sold at a discount to their fundamental value. Note that the buyers in the secondary market can perfectly identify each asset so that each asset has to offer the same rate of return, i.e. suffer the same proportional discount $1-\Delta$, where $\Delta=C / V$. Hence, the price in the secondary market for an asset sold by a borrower of type $i$ has to satisfy $P_{i}=\Delta \times R_{i} \cdot{ }^{27}$

In this case, liquidations lead to a loss of $(1-\Delta) R_{i}$, which is the only difference in the first-order condition in equation (5). We can easily show that $\partial b_{i} / \partial \Delta>0$ and $\partial q / \partial \Delta>0$ as in Proposition 3 and Corollary 2, respectively. Hence, for $d \Delta / d r>0$, we get the additional dampening effect on output due to the indirect effect through the price in the secondary market.

Note that the equilibrium liquidation value is implicitly defined by the fixed-point condition:

$$
\Delta \times V(r, \Delta)=C
$$

We can show that we still have equilibrium comovement between the liquidation values and the interest rate.

Corollary 4. With cash-in-the-market pricing, the liquidation values $P_{i}=\Delta R_{i}$ and the interest rate $r$ are positively related, i.e. $d \Delta / d r>0$.

This implies that insufficient market liquidity leads to a drop in the equilibrium liquidation values at $t=1$ if more funds are injected at $t=0, d P_{i} / d L<0$ for all $i$. This affects $d r / d L$ through the indirect effect of (10); monetary stimulus increases aggregate investment but at the same time lowers the interim liquidation values, leading to a dampening effect on output.

Hence, asymmetric information in the secondary market is not essential to get the dampening effect on output due to the indirect effect through the price and we can get

\footnotetext{
${ }^{27}$ Note that the two prices $P_{h}$ and $P_{\ell}$ are still linked through the common $\Delta$. This link is simply a noarbitrage condition equalizing the returns $R_{h} / P_{h}=R_{\ell} / P_{\ell}$ and ensuring that buyers are indifferent between buying from a high type or a low type. As long as we allow for arbitrage across the markets for the two types' assets, the only way the equilibrium prices would not be linked is if they were each equal to the assets' fundamental value, $P_{h}=R_{h}$ and $P_{\ell}=R_{\ell}$, in which case there would be no cost associated with liquidity risk (see footnote 26).
} 
similar effects even when buyers of the assets can perfectly distinguish the quality of the assets being sold. Furthermore, while we assume that liquidity in the secondary market is fixed at $C$, this is not necessary for our results. As long as capital is sufficiently slow-moving (Mitchell et al., 2007; Duffie, 2010; Acharya et al., 2013), there is cash-in-the-market pricing in the secondary market and our results go through qualitatively.

\section{Conclusion}

We build a general equilibrium model with heterogeneous agents facing financial frictions and show that monetary policy can become less effective than desired in stimulating output. More productive borrowers choose to invest more, but at the same time their higher leverage exposes them to higher liquidity risk. All borrowers increase their debt when monetary policy reduces interest rates, but this additional risk taking is greater for less productive borrowers because high productivity borrowers are reluctant to lever up further. This, in turn, dampens the effect of monetary stimulus on output even in the absence of price effects.

Furthermore, the drop in the overall quality of investment decreases liquidation values of opaque assets and thereby increases liquidity risk. The elevated liquidity risk then depresses aggregate loan demand, which lowers the interest rate further. This again affects borrowers differently and further decreases investment quality. When the economy is trapped in this negative spiral, aggregate output becomes less sensitive to monetary policy (potentially decreasing) even with a significant reduction in the interest rate. Since our model assumes neither decreasing returns to scale, nor agency problems or inherently inefficient liquidation, this effect is purely driven by endogenous credit reallocation among heterogeneous agents.

In response to the prominence of liquidity problems in the recent crisis, the Basel Committee has introduced new liquidity regulations such as the Liquidity Coverage Ratio (LCR) and the Net Stable Funding Ratio (NSFR). Our paper provides a new perspective on the interaction of such liquidity requirements and monetary policy implementation. In our model, liquidity risk impedes the transmission of monetary policy. The new liquidity requirements aim at containing the maturity and liquidity mismatch on the balance sheets of financial intermediaries. By reducing liquidity risk exposure ex ante, the regulations are therefore beneficial not just for financial stability but also for the transmission of monetary policy.

Finally, although the heterogeneous response underlying the dampening mechanism in our model relies on liquidity risk that is increasing in leverage, any other cost that is 
similarly increasing in balance sheet size can generate the heterogeneous response. For example, such costs could be from regulatory burden or the cost of deviating from a target leverage ratio. When the interest rate decreases, traditional banks facing regulatory costs respond less compared to shadow banks with less regulatory burden. Hence, our mechanism is consistent with a relative growth of the shadow banking sector in response to prolonged monetary loosening. More resources are allocated to "opaque" shadow banks and as a result secondary markets can become more illiquid, generating a negative feedback analogous to the one described in our paper. 


\section{References}

Acharya, V., S. T. Bharath, and A. Srinivasan (2006). Does industry-wide distress affect defaulted firms? Evidence from creditor recoveries. Journal of Financial Economics 85(3), 787-821.

Acharya, V. and H. Naqvi (2019). On reaching for yield and the coexistence of bubbles and negative bubbles. Journal of Financial Intermediation 38, 1-10.

Acharya, V. and S. Viswanathan (2011). Leverage, moral hazard, and liquidity. Journal of Finance 66(1), 99-138.

Acharya, V. V., H. S. Shin, and T. Yorulmazer (2013). A theory of arbitrage capital. Review of Corporate Finance Studies 2(1), 62-97.

Acharya, V. V. and A. V. Thakor (2016). The dark side of liquidity creation: Leverage and systemic risk. Journal of Financial Intermediation 28, 4-21.

Acharya, V. V. and T. Yorulmazer (2007). Too many to fail - An analysis of timeinconsistency in bank closure policies. Journal of Financial Intermediation 16(1), 1-31.

Adrian, T. and H. S. Shin (2010). Financial intermediaries and monetary economics. In B. M. Friedman and M. Woodford (Eds.), Handbook of Monetary Economics. Elsevier.

Agarwal, S., S. Chomsisengphet, N. Mahoney, and J. Stroebel (2015). Do banks pass through credit expansions? The marginal profitability of consumer lending during the great recession. Working Paper.

Aghion, P. and P. Bolton (1992). An incomplete contracts approach to financial contracting. The Review of Economic Studies 59(3), 473-494.

Allen, F., E. Carletti, I. Goldstein, and A. Leonello (2014). Government guarantees and financial stability. Working Paper.

Allen, F. and D. Gale (1994). Limited market participation and volatility of asset prices. American Economic Review 84(4), 933-955.

Allen, F. and D. Gale (1998). Optimal financial crises. Journal of Finance 53(4), 1245-1284.

Altunbas, Y., L. G. and D. Marques-Ibanez (2014). Does monetary policy affect bank risk? International Journal of Central Banking 10(1), 95-135.

Auclert, A. (2015). Monetary policy and the redistribution channel. Working Paper. 
Benmelech, E. and N. K. Bergman (2012). Credit traps. American Economic Review 102(6), 3004-3032.

Berger, A. N. and C. H. Bouwman (2013). How does capital affect bank performance during financial crises? Journal of Financial Economics 109(1), 146-176.

Bernanke, B. and M. Gertler (1989). Agency costs, net worth, and business fluctuations. American Economic Review 79(1), 14-31.

Bernanke, B. and M. Gertler (1995). Inside the black box: The credit channel of monetary policy transmission. Journal of Economic Perspectives 9(4), 27-48.

Bernanke, B. S. and A. S. Blinder (1992). The federal funds rate and the channels of monetary transmission. American Economic Review 82(4), 901-921.

Bianchi, J. and S. Bigio (2014). Banks, liquidity management and monetary policy. Working Paper.

Bolton, P., T. Santos, and J. Scheinkman (2011). Inside and outside liquidity. Quarterly Journal of Economics 126(1), 259-321.

Borio, C. and H. Zhu (2012). Capital regulation, risk-taking and monetary policy: A missing link in the transmission mechanism? Journal of Financial Stability 8(4), 236-251.

Brunnermeier, M. K., T. M. Eisenbach, and Y. Sannikov (2013). Macroeconomics with financial frictions: A survey. In D. Acemoglu, M. Arellano, and E. Dekel (Eds.), Advances in Economics and Econometrics, Tenth World Congress of the Econometric Society. Cambridge University Press.

Brunnermeier, M. K. and M. Oehmke (2013). The maturity rat race. Journal of Finance 68(2), 483-521.

Brunnermeier, M. K. and Y. Sannikov (2014). A macroeconomic model with a financial sector. American Economic Review 104(2), 379-421.

Brunnermeier, M. K. and M. Yogo (2009). A note on liquidity risk management. American Economic Review 99(2), 578-583.

Bruno, V. and H. S. Shin (2015). Cross-border banking and global liquidity. Review of Economic Studies 82(2), 535-564.

Calomiris, C. W. and C. M. Kahn (1991). The role of demandable debt in structuring optimal banking arrangements. American Economic Review 81(3), 497-513. 
Choi, D. B., T. M. Eisenbach, and T. Yorulmazer (2016). Sooner or later: Timing of monetary policy with heterogeneous risk-taking. American Economic Review (Papers and Proceedings) 106(5), 490-495.

Coval, J. and E. Stafford (2007). Asset fire sales (and purchases) in equity markets. Journal of Financial Economics 86(2), 479 - 512.

Dang, T. V., G. B. Gorton, and B. Holmström (2012). Ignorance, debt and financial crises. Working Paper, Yale University.

De Nicolò, G., G. Dell'Ariccia, L. Laeven, and F. Valencia (2010). Monetary policy and bank risk-taking. IMF Working Paper.

Dell'Ariccia, G., L. Laeven, and R. Marquez (2014). Real interest rates, leverage and bank risk-taking. Journal of Economic Theory 149, 65-99.

Dell'Ariccia, G., L. Laeven, and G. Suarez (2016). Bank leverage and monetary policy's risk-taking channel: Evidence from the United States. Journal of Finance (forthcoming).

DeMarzo, P. M. and D. Duffie (1999). A liquidity-based model of security design. Econometrica 67(1), 65-99.

Di Maggio, M., A. Kermani, and R. Ramcharan (2015). Monetary policy pass-through: Household consumption and voluntary deleveraging. Working Paper.

Diamond, D. W. (1991). Debt maturity structure and liquidity risk. The Quarterly Journal of Economics 106(3), 709-737.

Diamond, D. W. and P. H. Dybvig (1983). Bank runs, deposit insurance, and liquidity. Journal of Political Economy 91(3), 401-419.

Diamond, D. W. and R. G. Rajan (2001). Liquidity risk, liquidity creation, and financial fragility: A theory of banking. Journal of Political Economy 109(2), 287-327.

Diamond, D. W. and R. G. Rajan (2011). Fear of fire sales, illiquidity seeking, and credit freezes. Quarterly Journal of Economics 126(2), 557-591.

Duffie, D. (2010). Asset price dynamics with slow-moving capital. Journal of Finance 65(4), $1237-1267$.

Eisenbach, T. M. (2016). Rollover risk as market discipline: A two-sided inefficiency. Journal of Financial Economics (forthcoming). 
Eisenbach, T. M., T. Keister, J. McAndrews, and T. Yorulmazer (2014). Stability of funding models: An analytical framework. Federal Reserve Bank of New York Economic Policy Review 20(1), 29-49.

Ellul, A., C. Jotikasthira, and C. T. Lundblad (2011). Regulatory pressure and fire sales in the corporate bond market. Journal of Financial Economics 101(3), $596-620$.

Farhi, E. and J. Tirole (2012). Collective moral hazard, maturity mismatch, and systemic bailouts. American Economic Review 102(1), 60-93.

Flannery, M., S. Kwan, and M. Nimalendran (2013). The 2007-2009 financial crisis and bank opaqueness. Journal of Financial Intermediation 22, 55-84.

Flannery, M. J. (1986). Asymmetric information and risky debt maturity choice. Journal of Finance 41(1), 19-37.

Gale, D. and M. Hellwig (1985). Incentive-compatible debt contracts: The one-period problem. Review of Economic Studies 52(4), 647-663.

Gale, D. and T. Yorulmazer (2013). Liquidity hoarding. Theoretical Economics 8(2), 291-324.

Gambacorta, L. and H. S. Shin (2018). Why bank capital matters for monetary policy. Journal of Financial Intermediation 35, 17-29.

Goldstein, I. and A. Pauzner (2005). Demand-deposit contracts and the probability of bank runs. Journal of Finance 60(3), 1293-1327.

Grossman, S. J. and M. H. Miller (1988). Liquidity and market structure. Journal of Finance 43(3), 617-633.

Hanson, S. G., A. K. Kashyap, and J. C. Stein (2011). A macroprudential approach to financial regulation. Journal of Economic Perspectives 25(1), 3-28.

Hart, O. and J. Moore (1994). A theory of debt based on the inalienability of human capital*. The Quarterly Journal of Economics 109(4), 841-879.

Hirtle, B. (2006). Stock market reaction to financial statement certification by bank holding company CEOs. Journal of Money, Credit and Banking 38, 1263-1291.

Ho, T. and H. R. Stoll (1981). Optimal dealer pricing under transactions and return uncertainty. Journal of Financial Economics 9(1), $47-73$. 
Innes, R. D. (1990). Limited liability and incentive contracting with ex-ante action choices. Journal of Economic Theory 52(1), 45-67.

Ioannidou, V., S. Ongena, and J. L. Peydró (2015). Monetary policy, risk-taking and pricing: Evidence from a quasi-natural experiment. Review of Finance 19(1), 95-144.

Ippolito, F., A. K. Ozdagli, and A. Perez (2015). The transmission of monetary policy through bank lending: The floating rate channel. Working Paper.

James, C. (1991). The losses realized in bank failures. Journal of Finance 46(4), 1223-1242.

Jensen, M. C. (1986). Agency costs of free cash flow, corporate finance, and takeovers. The American Economic Review 76(2), 323-329.

Jiménez, G., S. Ongena, J. L. Peydró, and J. Saurina (2014). Hazardous times for monetary policy: What do twenty-three million bank loans say about the effects of monetary policy on credit risk-taking? Econometrica 82(2), 463-505.

Justiniano, A., G. Primiceri, and A. Tambalotti (2015). Credit supply and the housing boom. Working Paper.

Kashyap, A. K. and J. C. Stein (1995). The impact of monetary policy on bank balance sheets. Carnegie-Rochester Conference Series on Public Policy 42, 151-195.

Kashyap, A. K. and J. C. Stein (2000). What do a million observations on banks say about the transmission of monetary policy? American Economic Review 90(3), 407-428.

Kashyap, A. K., D. P. Tsomocos, and A. P. Vardoulakis (2014). How does macroprudential regulation change bank credit supply? NBER Working Paper.

Keister, T. (2016). Bailouts and financial fragility. Review of Economic Studies 83, 460-480.

Keys, B., T. Piskorski, A. Seru, and V. W. Yao (2014). Mortgage rates, household balance sheets, and the real economy. Working Paper.

Kiyotaki, N. and J. Moore (1997). Credit cycles. Journal of Political Economy 105(2), 211-248.

Kurlat, P. (2013). Lemons markets and the transmission of aggregate shocks. American Economic Review 103(4), 1463-1489.

Malherbe, F. (2014). Self-fulfilling liquidity dry-ups. Journal of Finance 69(2), 947-970. 
Mitchell, M., L. H. Pedersen, and T. Pulvino (2007). Slow moving capital. American Economic Review 97(2), 215-220.

Morgan, D. (2002). Rating banks: Risk and uncertainty in an opaque industry. American Economic Review 92(4), 874-888.

Morris, S. and H. S. Shin (2003). Global games: Theory and applications. In M. Dewatripont, L. P. Hansen, and S. J. Turnovsky (Eds.), Advances in Economics and Econometrics, Eighth World Congress of the Econometric Society. Cambridge University Press.

Morris, S. and H. S. Shin (2010). Illiquidity component of credit risk. Working Paper.

Myers, S. C. and N. S. Majluf (1984). Corporate financing and investment decisions when firms have information that investors do not have. Journal of Financial Economics 13(2), $187-221$.

Nachman, D. C. and T. H. Noe (1994). Optimal design of securities under asymmetric information. Review of Financial Studies 7(1), 1-44.

Paligorova, T. and J. A. C. Santos (2012). Monetary policy and bank risk-taking: Evidence from the corporate loan market. Working Paper.

Pérignon, C., D. Thesmar, and G. Vuillemey (2018). Wholesale funding dry-ups. Journal of Finance 73(2), 575-617.

Peydró, J. L. and A. Maddaloni (2011). Bank risk-taking, securitization, supervision, and low interest rates: Evidence from the Euro area and U.S. lending standards. Review of Financial Studies 24, 2121-2165.

Pulvino, T. C. (1998). Do asset fire sales exist: An empirical investigation of commercial aircraft sale transactions. Journal of Finance 53, 939-978.

Shin, H. S. (2009). Reflections on Northern Rock: The bank run that heralded the global financial crisis. Journal of Economic Perspectives 23(1), 101-119.

Shleifer, A. and R. W. Vishny (1992). Liquidation values and debt capacity: A market equilibrium approach. Journal of Finance 47(4), 1343-1366.

Shleifer, A. and R. W. Vishny (2011). Fire sales in finance and macroeconomics. Journal of Economic Perspectives 25(1), 29-48.

Stein, J. (2014). Incorporating financial stability considerations into a monetary policy framework. Speech at the IMF Spring Meetings on April 13, 2014. 
Stein, J. C. (2012). Monetary policy as financial-stability regulation. Quarterly Journal of Economics 127(1), 57-95.

Stiglitz, J. and A. Weiss (1981). Credit rationing in markets with imperfect information. American Economic Review 71(3), 393-410.

Sufi, A. (2015). Out of many, one? Household debt, redistribution and monetary policy during the economic slump. Andrew Crockett Memorial Lecture.

Svensson, L. E. (2003). Comment on: The future of monetary aggregates in monetary policy analysis. Journal of Monetary Economics 50(5), 1061-1070.

Tarullo, D. (2014). Monetary policy and financial stability. Speech at the 30th Annual National Association for Business Economics Economic Policy Conference on February $25,2014$.

Thakor, A. V. (1996). Capital requirements, monetary policy, and aggregate bank lending: Theory and empirical evidence. Journal of Finance 51(1), 279-324.

Townsend, R. M. (1979). Optimal contracts and competitive markets with costly state verification. Journal of Economic Theory 21(2), 265-293.

Williamson, O. E. (1988). Corporate finance and corporate governance. Journal of Finance 43(3), 567-591. 


\section{Appendix}

\section{A Proofs}

Proof of Lemma 1. The creditors of borrower type $i$ are promised an interest rate $r_{i}$ on their loan $D$. If there is no run in $t=1$, which happens with probability $1-\alpha$, they receive $\left(1+r_{i}\right) D$. If there is a run in $t=1$, which happens with probability $\alpha$, the entire project is liquidated and the creditors receive the lesser of their face value or the liquidation value of the borrower's assets, i.e. $\min \left\{\left(1+r_{i}\right) D, P(D+e)\right\}$. For the creditors of type $i$ to break even, given a risk free rate of $r$, the promised interest rate $r_{i}$ therefore has to satisfy:

$$
(1-\alpha(b))\left(1+r_{i}\right) D+\alpha(b) \min \left\{\left(1+r_{i}\right) D, P(D+e)\right\}=(1+r) D
$$

With limited liability, the borrower is the claimant to any positive residual payoff. If there is no run, the borrower type $i$ receives the project payoff net of debt repayment, i.e. $R_{i}(D+e)-\left(1+r_{i}\right) D$ (we verify below that this is nonnegative). If there is a run, the borrower receives whatever is left over after repaying the creditors, i.e. $\max \left\{P(D+e)-\left(1+r_{i}\right) D, 0\right\}$. The expected payoff of borrower type $i$ at $t=0$ therefore is:

$$
(1-\alpha(b))\left(R_{i}(D+e)-\left(1+r_{i}\right) D\right)+\alpha(b) \max \left\{P(D+e)-\left(1+r_{i}\right) D, 0\right\}
$$

To eliminate the interest rate $r_{i}$ from the borrower payoff (22) using the creditor breakeven condition (21), note that we can rewrite the borrower payoff (22) as:

$$
\begin{aligned}
& (1-\alpha(b)) R_{i}(D+e)+\alpha(b) P(D+e) \\
& \quad-\left[(1-\alpha(b))\left(1+r_{i}\right) D-\alpha(b) \max \left\{-\left(1+r_{i}\right) D,-P(D+e)\right\}\right]
\end{aligned}
$$

Using the fact that $-\max \{-a,-b\}=\min \{a, b\}$, we can rewrite this expression as:

$$
\begin{aligned}
& (1-\alpha(b)) R_{i}(D+e)+\alpha(b) P(D+e) \\
& \quad-\left[(1-\alpha(b))\left(1+r_{i}\right) D+\alpha(b) \min \left\{\left(1+r_{i}\right) D, P(D+e)\right\}\right]
\end{aligned}
$$

Note that the term in square brackets on the second line of this expression is the same as the left-hand side of the breakeven condition (21). Combining the two, we therefore arrive at the expected payoff as stated in the Lemma:

$$
\Pi_{i}(D ; r, P)=\alpha(b) P(D+e)+(1-\alpha(b)) R_{i}(D+e)-(1+r) D
$$


It remains to verify that $R_{i}(D+e)-\left(1+r_{i}\right) D \geq 0$ as assumed above. Note that it is sufficient to show this for $\left(1+r_{i}\right) D \geq P(D+e)$, in which case we can rewrite condition (21) as:

$$
\left(1+r_{i}\right) D=\frac{(1+r) D-\alpha(b) P(D+e)}{1-\alpha(b)}
$$

Using this expression, we have:

$$
\begin{aligned}
& R_{i}(D+e)-\left(1+r_{i}\right) D \geq 0 \\
& \Leftrightarrow \quad R_{i}(D+e)-\frac{(1+r) D-\alpha(b) P(D+e)}{1-\alpha(b)} \geq 0 \\
& \Leftrightarrow \quad \Pi_{i}(D ; r, P) \geq 0
\end{aligned}
$$

This is clearly satisfied for any borrower optimally choosing $D \geq 0$ since any agent can guarantee herself at least $\Pi_{i}(0 ; r, P)=0$.

Proof of Proposition 1. For simplicity, we suppress the subscript $i$ in $R_{i}$ and $b_{i}$. From the implicit function theorem, the first order condition (5) implies:

$$
\frac{\partial b}{\partial R}=\frac{\left(1-\alpha^{\prime}(b) b-\alpha(b)\right)}{\left(\alpha^{\prime \prime}(b) b+2 \alpha^{\prime}(b)\right)(R-P)}
$$

Note that the denominator is positive. The numerator is also positive since the first order condition implies

$$
\begin{aligned}
\alpha^{\prime}(b) b+\alpha(b) & =\frac{R-(1+r)}{R-P} \\
& <1 \text { for } P<1+r
\end{aligned}
$$

Therefore $\partial b / \partial R$ is positive and thus $b_{h}>b_{\ell}$.

Proof of Proposition 2. Note that by the implicit function theorem, we have:

$$
\frac{\partial b_{i}}{\partial r}=\frac{-1}{\left(\alpha^{\prime \prime}\left(b_{i}\right) b_{i}+2 \alpha^{\prime}\left(b_{i}\right)\right)\left(R_{i}-P\right)}<0
$$

The denominator is larger for the high type since $R_{h}>R_{\ell}, b_{h}>b_{\ell}$, with $\alpha(b)^{\prime \prime} \geq 0$ and $\alpha(b)^{\prime \prime \prime} \approx 0$ so that $\left|\partial b_{h} / \partial r\right|<\left|\partial b_{\ell} / \partial r\right|$. 
Proof of Proposition 3. From the implicit function theorem, the first order condition implies

$$
\frac{\partial b_{i}}{\partial P}=\frac{\alpha^{\prime}\left(b_{i}\right) b_{i}+\alpha\left(b_{i}\right)}{\left(\alpha^{\prime \prime}\left(b_{i}\right) b_{i}+2 \alpha^{\prime}\left(b_{i}\right)\right)\left(R_{i}-P\right)}>0
$$

Note that the denominator is positive as before. The numerator is also positive since all terms are positive. Thus $\partial b_{i} / \partial P$ is positive.

From the first order condition we have

$$
\alpha^{\prime}\left(b_{i}\right) b_{i}+\alpha\left(b_{i}\right)=\frac{R_{i}-(1+r)}{R_{i}-P}
$$

so that $\partial b_{h} / \partial P>\partial b_{\ell} / \partial P$ if and only if

$$
\frac{\alpha^{\prime \prime}\left(b_{h}\right) b_{h}+2 \alpha^{\prime}\left(b_{h}\right)}{\alpha^{\prime \prime}\left(b_{\ell}\right) b_{\ell}+2 \alpha^{\prime}\left(b_{\ell}\right)}<\frac{\left(R_{h}-(1+r)\right) /\left(R_{h}-P\right)^{2}}{\left(R_{\ell}-(1+r)\right) /\left(R_{\ell}-P\right)^{2}}
$$

as stated in the proposition.

Proof of Corollary 1. Since $R_{\ell}<R_{h}$, we have $q-R_{\ell}>0>q-R_{h}$. Further, since $b_{h}>b_{\ell}, q$ is biased towards $R_{h}$ so $\sum_{i}\left(q-R_{i}\right)>0$. From Proposition 2 , we have $-\partial b_{\ell} / \partial r>$ $-\partial b_{h} / \partial r$ so that

$$
-\sum_{i}\left(\left(q-R_{i}\right) \frac{\partial b_{i}}{\partial r}\right)>-\sum_{i}\left(q-R_{i}\right) \frac{\partial b_{h}}{\partial r}>0
$$

and therefore $\partial q / \partial r>0$.

Proof of Corollary 2. First, note that $\partial Q / \partial r>0$ and $\partial Q / \partial P<1 / \delta$ are sufficient for $d P / d r>0$ from (14). This is also sufficient for a positive indirect effect in (10) since $\partial b_{i} / \partial P>0$ from Proposition 3.

Second, $\partial Q / \partial r>0$ and $\partial Q / \partial P<1 / \delta$ are sufficient for $d P / d r>0$, and this with $\partial q / \partial P>0$ implies the indirect effect in (8) is positive, which amplifies the quality elasticity.

Third, using the definition of $Q$, we have that $\partial Q / \partial r>0$ holds if

$$
-\sum_{i}\left(\left(Q-R_{i}\right) \partial\left(\alpha\left(b_{i}\right) b_{i}\right) / \partial r\right)>0
$$

Using

$$
\frac{\partial\left(\alpha\left(b_{i}\right) b_{i}\right)}{\partial r}=\left(\alpha^{\prime}\left(b_{i}\right) b_{i}+\alpha\left(b_{i}\right)\right) \frac{\partial b_{i}}{\partial r}=-\frac{\partial b_{i}}{\partial P}
$$


(23) can be written as

$$
\frac{\partial b_{\ell}}{\partial P}>\frac{R_{h}-Q}{Q-R_{\ell}} \frac{\partial b_{h}}{\partial P} \equiv \beta_{1} \frac{\partial b_{h}}{\partial P}
$$

and $\partial Q / \partial P<1 / \delta$ holds if

$$
-\left(Q-R_{\ell}\right) \frac{\partial\left(\alpha\left(b_{\ell}\right) b_{\ell}\right)}{\partial P}-\left(Q-R_{h}\right) \frac{\partial\left(\alpha\left(b_{h}\right) b_{h}\right)}{\partial P}<\frac{\alpha\left(b_{h}\right) b_{h}+\alpha\left(b_{\ell}\right) b_{\ell}}{\delta},
$$

which can be written as

$$
\begin{aligned}
\frac{\partial b_{\ell}}{\partial P} & >\frac{\left(R_{h}-Q\right)\left(\alpha^{\prime}\left(b_{h}\right) b_{h}+\alpha\left(b_{h}\right)\right)}{\left(Q-R_{\ell}\right)\left(\alpha^{\prime}\left(b_{\ell}\right) b_{\ell}+\alpha\left(b_{\ell}\right)\right)} \frac{\partial b_{h}}{\partial P}-\frac{\alpha\left(b_{h}\right) b_{h}+\alpha\left(b_{\ell}\right) b_{\ell}}{\left(Q-R_{\ell}\right)\left(\alpha^{\prime}\left(b_{\ell}\right) b_{\ell}+\alpha\left(b_{\ell}\right)\right) \delta} \\
& \equiv \beta_{3} \frac{\partial b_{h}}{\partial P}-\gamma ;
\end{aligned}
$$

and $\partial q / \partial P>0$ holds if

$$
\left(q-R_{\ell}\right) \frac{\partial b_{\ell}}{\partial P}<\left(R_{h}-q\right) \frac{\partial b_{h}}{\partial P}
$$

which can be written as

$$
\frac{\partial b_{\ell}}{\partial P}<\frac{R_{h}-q}{q-R_{\ell}} \frac{\partial b_{h}}{\partial P} \equiv \beta_{2} \frac{\partial b_{h}}{\partial P} .
$$

Similarly, $\partial Q / \partial P>0$ holds if

$$
-\sum_{i}\left(\left(Q-R_{i}\right) \partial\left(\alpha\left(b_{i}\right) b_{i}\right) / \partial P\right)>0
$$

and thus

$$
\left(Q-R_{\ell}\right)\left(\alpha^{\prime}\left(b_{\ell}\right) b_{\ell}+\alpha\left(b_{\ell}\right)\right) \frac{\partial b_{\ell}}{\partial P}<\left(R_{h}-Q\right)\left(\alpha^{\prime}\left(b_{h}\right) b_{h}+\alpha\left(b_{h}\right)\right) \frac{\partial b_{h}}{\partial P}
$$

which can be written as

$$
\frac{\partial b_{\ell}}{\partial P}<\frac{\left(R_{h}-Q\right)\left(\alpha^{\prime}\left(b_{h}\right) b_{h}+\alpha\left(b_{h}\right)\right)}{\left(Q-R_{\ell}\right)\left(\alpha^{\prime}\left(b_{\ell}\right) b_{\ell}+\alpha\left(b_{\ell}\right)\right)} \frac{\partial b_{h}}{\partial P}=\beta_{3} \frac{\partial b_{h}}{\partial P} .
$$

Now, note that $\beta_{2}>\beta_{1}>0$ with $Q>q, \beta_{3}>\beta_{1}>0$ with $b_{h}>b_{l}$, while $\gamma>0$. Therefore, (24), (25), (26), and (27) are not mutually exclusive. 
Proof of Corollary 3. Note that

$$
\frac{\left|\frac{\partial b_{h} / \partial P}{\partial b_{\ell} / \partial P}\right|}{\left|\frac{\partial b_{h} / \partial r}{\partial b_{\ell} / \partial r}\right|}=\frac{\alpha^{\prime}\left(b_{h}\right) b_{h}+\alpha\left(b_{h}\right)}{\alpha^{\prime}\left(b_{\ell}\right) b_{\ell}+\alpha\left(b_{\ell}\right)}=\frac{\left(R_{h}-(1+r)\right) /\left(R_{h}-P\right)^{2}}{\left(R_{\ell}-(1+r)\right) /\left(R_{\ell}-P\right)^{2}}>1
$$

since $1+r>P$ and $b_{h}>b_{\ell}$.

Proof of Corollary 4. Given this implicit definition of $\Delta$ in (20), the equilibrium effect of $r$ on $\Delta$ is given by

$$
\frac{d \Delta}{d r}=-\frac{\Delta \partial V / \partial r}{V+\Delta \partial V / \partial \Delta}
$$

and sufficient conditions for $d \Delta / d r>0$ are $\partial V / \partial r<0$ and $\partial V / \partial \Delta>0$. We obtain

$$
\begin{aligned}
& \frac{\partial V}{\partial r}=\sum_{i}\left(\alpha^{\prime}\left(b_{i}\right) b_{i}+\alpha\left(b_{i}\right)\right) \frac{\partial b_{i}}{\partial r} R_{i}<0 \\
& \frac{\partial V}{\partial \Delta}=\sum_{i}\left(\alpha^{\prime}\left(b_{i}\right) b_{i}+\alpha\left(b_{i}\right)\right) \frac{\partial b_{i}}{\partial P_{i}} R_{i}^{2}>0
\end{aligned}
$$

since $\partial b_{i} / \partial r<0$ from Proposition 2 and $\partial b_{i} / \partial P_{i}>0$ from Proposition $3 .^{28}$ Hence, we obtain

$$
\frac{d P_{i}}{d r}=\frac{d \Delta}{d r} R_{i}>0
$$

as desired.

\section{B Liquidity risk}

\section{B.1 Example microfoundations}

In this appendix, we provide two simple microfoundations that result in a liquidity risk function $\alpha(b)$ with the features assumed in the main text, i.e., independent of type $i=h, \ell$, and increasing in leverage $b$.

Random withdrawals due to consumption needs. At $t=1$, a random fraction $\phi$ of creditors withdraw due to, e.g., consumption needs, where $\phi$ is distributed i.i.d. across borrowers with c.d.f. $F$. The borrower can satisfy withdrawals by liquidating assets or by raising new debt. If the borrower were to meet withdrawals equal to $\phi D$ by liquidating

\footnotetext{
${ }^{28}$ Making the liquidation value type-dependent does not affect the comparative statics of individual borrowing with respect to $r$ or $P_{i}$.
} 
assets, discounted by a factor $\lambda<1$, she would remain solvent at $t=1$ as long as

$$
\underbrace{I-\frac{\phi D}{\lambda}}_{\text {remaining assets }} \geq \underbrace{(1-\phi) D}_{\text {remaining debt }}
$$

This condition implies a critical level of withdrawals $\phi^{*}=\lambda /((b-1)(1-\lambda))$ such that the borrower is solvent for $\phi \leq \phi^{*}$ and insolvent otherwise. Note that, given a leverage $b$, this threshold is independent of the borrower's type. This is because all types receive the same liquidation value in the secondary market, hence face the same discount $\lambda$.

Assume that, as long as the borrower is solvent according to condition (28), she is able to replace the funding withdrawn with new funding from other creditors and does not have to liquidate any assets. If, however, withdrawals are so large that they would cause insolvency, no outside creditor is willing to replace the withdrawn funding and the borrower faces a full-blown run. The probability of facing a run and being forced to liquidate, therefore is

$$
\operatorname{Pr}\left[\phi>\phi^{*}\right]=1-F\left(\frac{\lambda}{(1-\lambda)(b-1)}\right) \equiv \alpha(b),
$$

which is independent of type $i=h, \ell$.

Note that we immediately have $\alpha^{\prime}(b)>0$. We further have

$$
\alpha^{\prime \prime}(b)=-\left(f^{\prime}\left(\phi^{*}\right) \phi^{*}+2 f\left(\phi^{*}\right)\right) \frac{\phi^{*}}{(b-1)^{2}}
$$

Hence, for the liquidity risk $\alpha(b)$ to be weakly convex, we need

$$
\phi^{*} f^{\prime}\left(\phi^{*}\right)+2 f\left(\phi^{*}\right) \leq 0
$$

That is, the insolvency threshold $\phi^{*}$ has to be in the right tail of the distribution of withdrawals due to idiosyncratic consumption needs, where the density $f(\phi)$ is small and decreasing, $f^{\prime}(\phi)<0 .{ }^{29}$ This is naturally satisfied for many distributions, as it simply means that larger and larger withdrawals due to consumption needs are less and less likely.

Noisy signals about fundamental. We now provide an alternative micro-foundation for liquidity risk using global game techniques analogous to the analysis in Eisenbach

\footnotetext{
${ }^{29}$ Note that $F$ is the distribution of withdrawals due to consumption needs, which can lead to insolvency and thereby trigger a run, not the distribution of runs that are triggered by insolvency.
} 
(2016).$^{30}$ We therefore introduce some project risk by assuming that a type-i agent's project pays off $\bar{R}_{i}$ at $t=2$ with probability $p$ and 0 otherwise. We can interpret the success probability $p$ as a macroeconomic variable common across all types as of $t=0$, and $\bar{R}_{i}$ as the idiosyncratic productivity of type $i$. We assume that $\bar{R}_{i}$ is large enough to pay its debt fully at $t=2$. The return $R_{i}$ in the body of the text is then an expected return, $R_{i}=p \bar{R}_{i}$, without affecting any of our results. At $t=1$, each individual borrower $j$ (who can be of either type $i \in\{h, \ell\}$ ) receives an idiosyncratic shock to $p$, updating it to $p_{j}=p+u_{j}$ where the shock $u_{j}$ is i.i.d. across the two types with mean 0 and cumulative distribution function $F_{u}$ on $[\underline{u}, \bar{u}]$.

We normalize each borrower's creditors to a continuum of measure 1. Each creditor $k \in[0,1]$ can choose at $t=1$ whether to withdraw or roll over until $t=2$. Denote by $\varphi \in$ $[0,1]$ the fraction of creditors who choose to withdraw and by $r_{s}$ the one-period interest rate promised to creditors. Note that $r_{s}$ is endogenous and is set by an ex-ante break-even condition as shown below. The borrower fails at $t=1$ if total withdrawals are larger than the total liquidation value of the borrower's assets: ${ }^{31}$

$$
\varphi>\hat{\varphi} \equiv \frac{P b}{\left(1+r_{s}\right)(b-1)}
$$

The threshold $\hat{\varphi}$ is decreasing in $b$ so for higher leverage, a smaller fraction of withdrawals can cause failure. A creditor who withdraws at $t=1$ receives $\left(1+r_{s}\right) D$ if the borrower doesn't fail and the liquidation value plus initial net worth, $P(D+e)$, otherwise. A creditor who rolls over to $t=2$ expects to receive $p_{j}\left(1+r_{s}\right)^{2} D$ if the borrower survives and 0 otherwise.

We now introduce a global game setup so that a unique failure threshold $p_{j}^{*}$ can be derived where a borrower $j$ fails if $p_{j} \leq p_{j}^{*}$ and survives otherwise. Suppose that $p_{j}$ is not common knowledge and instead creditor $k$ of borrower $j$ receives an i.i.d. noisy signal $s_{k j}=$ $p_{j}+\varepsilon_{k j}$, where $\varepsilon_{k j}$ is uniformly distributed on $[-\varepsilon, \varepsilon]$. Each creditor then chooses whether to roll over or withdraw after observing her private signal. We focus on the threshold strategy equilibrium for $\varepsilon \rightarrow 0$ such that a creditor chooses to withdraw if and only if $s_{k j}<p_{j}^{*}$ for some threshold $p_{j}^{*}$.

A creditor exactly at the switching point, $s_{k j}=p_{j}^{*}$, has to be indifferent between the

\footnotetext{
${ }^{30}$ See Morris and Shin (2010) for a similar approach. Eisenbach et al. (2014) provide a model where banks can fail due to poor fundamentals and/or a loss of significant short-term funding as well as the interaction between the two.

${ }^{31}$ As above, we assume that the initial net worth is available to satisfy withdrawals.
} 
two actions which requires that

$$
\begin{aligned}
\operatorname{Pr}\left[\varphi \leq \hat{\varphi} \mid s_{k j}=p_{j}^{*}\right] \times\left(1+r_{s}\right) D+\operatorname{Pr}\left[\varphi>\hat{\varphi} \mid s_{k j}=p_{j}^{*}\right] \times P(D+e) \\
=\operatorname{Pr}\left[\varphi \leq \hat{\varphi} \mid s_{k j}=p_{j}^{*}\right] \times p_{j}^{*}\left(1+r_{s}\right)^{2} D+\operatorname{Pr}\left[\varphi>\hat{\varphi} \mid s_{k j}=p_{j}^{*}\right] \times 0
\end{aligned}
$$

For $\varepsilon \rightarrow 0$, the distribution of $\varphi$ conditional on $s_{k j}=p_{j}^{*}$ becomes uniform on $[0,1]$ (Morris and Shin, 2003; Goldstein and Pauzner, 2005) and the indifference condition simplifies to

$$
\hat{\varphi}\left(1+r_{s}\right) D+(1-\hat{\varphi}) P(D+e)=\hat{\varphi} p_{j}^{*}\left(1+r_{s}\right)^{2} D
$$

Substituting in for $\hat{\varphi}$ from (29) and solving for $p_{j}^{*}$ we get

$$
p_{j}^{*}=\frac{2\left(1+r_{s}\right)(b-1)-P b}{\left(1+r_{s}\right)^{2}(b-1)}
$$

For given $r_{s}$ the run threshold and therefore liquidity risk is increasing in $b$. Note, however, that $r_{s}$ is an endogenous variable that depends on $p_{j}^{*}$ and $D$. The interest rate $r_{s}$ is determined by a $t=0$ break-even condition for creditors:

$$
F_{u}\left(p_{j}^{*}-p\right) P(D+e)+\int_{p_{j}^{*}-p}^{\bar{u}}\left(p+u_{j}\right) d F_{u}(u)\left(1+r_{s}\right)^{2} D=(1+r) D
$$

The $t=1$ indifference condition (30) and the $t=0$ break-even condition (31) implicitly define the interim run threshold $p_{j}^{*}$ as a function of the ex-ante borrowing $D$ or, equivalently, leverage $b$. Lemma 1 of Eisenbach (2016) shows that the mapping $p_{j}^{*}(b)$ is one-to-one and satisfies $d p_{j}^{*} / d b>0$. Note that nothing in the defining equations depends on borrower $j$ or her type type $i \in\{h, \ell\}$ so we have a common threshold $p_{H}^{*}=p_{L}^{*} \equiv p^{*}$ for both types. Therefore, the ex-ante liquidity risk depends only on $b$,

$$
\alpha(b)=\operatorname{Pr}\left(p_{j} \leq p^{*} \mid p\right)=F_{u}\left(p^{*}(b)-p\right),
$$

and can thus write $\alpha$ as a function of $b$ but not type $i$, as we did in main part of the paper. Since $d p^{*} / d b>0$, we have $\alpha^{\prime}(b)>0$ as in the main text.

\section{B.2 Type-dependent liquidity risk}

In this appendix, we show that allowing for liquidity risk to depend on borrower type does not affect our results. Suppose we have liquidity risk $\alpha_{i}(b)$ depend on type $i=h, \ell$ 
with $\alpha_{h}(b)<\alpha_{\ell}(b)$ and $\alpha_{h}^{\prime}(b)<\alpha_{\ell}^{\prime}(b)$, i.e. compared to low types, high types have lower liquidity risk for given leverage $b$ and their liquidity risk increases more slowly. Typedependent liquidity risk reduces the cost of liquidity risk for the high type compared to the low type so the difference in leverage will be larger than before (Proposition 1).

For the heterogeneous response to the interest rate (Proposition 2), we need

$$
\frac{\alpha_{h}^{\prime \prime}\left(b_{h}\right) b_{h}+2 \alpha_{h}^{\prime}\left(b_{h}\right)}{\alpha_{\ell}^{\prime \prime}\left(b_{\ell}\right) b_{\ell}+2 \alpha_{\ell}^{\prime}\left(b_{\ell}\right)}>\frac{R_{\ell}-P}{R_{h}-P}
$$

which is satisfied if the difference in productivity $R_{i}$ is sufficiently large compared to the difference in liquidity risk $\alpha_{i}$. This is satisfied if the difference $R_{h}-R_{\ell}$ is sufficiently large.

For the heterogeneous response to the liquidation value (Proposition 3), we need

$$
\frac{\alpha_{h}^{\prime \prime}\left(b_{h}\right) b_{h}+2 \alpha_{h}^{\prime}\left(b_{h}\right)}{\alpha_{\ell}^{\prime \prime}\left(b_{\ell}\right) b_{\ell}+2 \alpha_{\ell}^{\prime}\left(b_{\ell}\right)}<\frac{\left(R_{h}-(1+r)\right) /\left(R_{h}-P\right)^{2}}{\left(R_{\ell}-(1+r)\right) /\left(R_{\ell}-P\right)^{2}} .
$$

Note that it is possible to satisfy both (32) and (33) since we have

$$
\begin{aligned}
& \frac{R_{\ell}-P}{R_{h}-P}<\frac{\left(R_{h}-(1+r)\right) /\left(R_{h}-P\right)^{2}}{\left(R_{\ell}-(1+r)\right) /\left(R_{\ell}-P\right)^{2}} \\
\Leftrightarrow \quad & \frac{R_{h}-P}{R_{\ell}-P}<\frac{R_{h}-(1+r)}{R_{\ell}-(1+r)},
\end{aligned}
$$

which is true since $P<1+r$.

Finally, we show that the conditions in Corollary 2 can be satisfied simultaneously, generating the feedback through the liquidation value. For simplicity, we keep the notation in Corollary 2. First, $\partial Q / \partial r>0$ holds if

$$
-\sum_{i}\left(\left(Q-R_{i}\right) \partial\left(\alpha_{i}\left(b_{i}\right) b_{i}\right) / \partial r\right)>0
$$

Using

$$
\frac{\partial\left(\alpha_{i}\left(b_{i}\right) b_{i}\right)}{\partial r}=\left(\alpha_{i}^{\prime}\left(b_{i}\right) b_{i}+\alpha_{i}\left(b_{i}\right)\right) \frac{\partial b_{i}}{\partial r}=-\frac{\partial b_{i}}{\partial P^{\prime}}
$$

(34) can be written as

$$
\frac{\partial b_{\ell}}{\partial P}>\frac{R_{h}-Q}{Q-R_{\ell}} \frac{\partial b_{h}}{\partial P} \equiv \beta_{1} \frac{\partial b_{h}}{\partial P} .
$$

Second, $\partial Q / \partial P<1 / \delta$ holds if

$$
-\left(Q-R_{\ell}\right) \frac{\partial\left(\alpha_{\ell}\left(b_{\ell}\right) b_{\ell}\right)}{\partial P}-\left(Q-R_{h}\right) \frac{\partial\left(\alpha_{h}\left(b_{h}\right) b_{h}\right)}{\partial P}<\frac{\alpha_{h}\left(b_{h}\right) b_{h}+\alpha_{\ell}\left(b_{\ell}\right) b_{\ell}}{\delta},
$$


which can be written as

$$
\begin{aligned}
\frac{\partial b_{\ell}}{\partial P} & >\frac{\left(R_{h}-Q\right)\left(\alpha_{h}^{\prime}\left(b_{h}\right) b_{h}+\alpha_{h}\left(b_{h}\right)\right)}{\left(Q-R_{\ell}\right)\left(\alpha_{\ell}^{\prime}\left(b_{\ell}\right) b_{\ell}+\alpha_{\ell}\left(b_{\ell}\right)\right)} \frac{\partial b_{h}}{\partial P}-\frac{\alpha_{h}\left(b_{h}\right) b_{h}+\alpha_{\ell}\left(b_{\ell}\right) b_{\ell}}{\left(Q-R_{\ell}\right)\left(\alpha_{\ell}^{\prime}\left(b_{\ell}\right) b_{\ell}+\alpha_{\ell}\left(b_{\ell}\right)\right) \delta} \\
& \equiv \beta_{3} \frac{\partial b_{h}}{\partial P}-\gamma .
\end{aligned}
$$

Third, $\partial q / \partial P>0$ holds if

$$
\left(q-R_{\ell}\right) \frac{\partial b_{\ell}}{\partial P}<\left(R_{h}-q\right) \frac{\partial b_{h}}{\partial P}
$$

which can be written as

$$
\frac{\partial b_{\ell}}{\partial P}<\frac{R_{h}-q}{q-R_{\ell}} \frac{\partial b_{h}}{\partial P} \equiv \beta_{2} \frac{\partial b_{h}}{\partial P} .
$$

Lastly, $\partial Q / \partial P>0$ holds if

$$
-\sum_{i}\left(\left(Q-R_{i}\right) \partial\left(\alpha_{i}\left(b_{i}\right) b_{i}\right) / \partial P\right)>0,
$$

and thus

$$
\left(Q-R_{\ell}\right)\left(\alpha_{\ell}^{\prime}\left(b_{\ell}\right) b_{\ell}+\alpha_{\ell}\left(b_{\ell}\right)\right) \frac{\partial b_{\ell}}{\partial P}<\left(R_{h}-Q\right)\left(\alpha_{h}^{\prime}\left(b_{h}\right) b_{h}+\alpha_{h}\left(b_{h}\right)\right) \frac{\partial b_{h}}{\partial P},
$$

which can be written as

$$
\frac{\partial b_{\ell}}{\partial P}<\frac{\left(R_{h}-Q\right)\left(\alpha_{h}^{\prime}\left(b_{h}\right) b_{h}+\alpha_{h}\left(b_{h}\right)\right)}{\left(Q-R_{\ell}\right)\left(\alpha_{\ell}^{\prime}\left(b_{\ell}\right) b_{\ell}+\alpha_{\ell}\left(b_{\ell}\right)\right)} \frac{\partial b_{h}}{\partial P}=\beta_{3} \frac{\partial b_{h}}{\partial P} .
$$

Again, note that $Q>q$ and $\gamma>0$ imply $\beta_{2}>\beta_{1}>0$ as in the proof of Corollary 2. It remains to show that $\beta_{3}>\beta_{1}$. Here, it is sufficient to show

$$
\frac{\alpha_{h}^{\prime}\left(b_{h}\right) b_{h}+\alpha_{h}\left(b_{h}\right)}{\alpha_{\ell}^{\prime}\left(b_{\ell}\right) b_{\ell}+\alpha_{\ell}\left(b_{\ell}\right)}>1 .
$$

From the first order condition, we have

$$
\alpha_{i}^{\prime}\left(b_{i}\right) b_{i}+\alpha_{i}\left(b_{i}\right)=\frac{R_{i}-(1+r)}{R_{i}-P} .
$$

Note that the RHS is increasing in $R_{i}$ since $P<1+r$, so that

$$
\alpha_{h}^{\prime}\left(b_{h}\right) b_{h}+\alpha_{h}\left(b_{h}\right)>\alpha_{\ell}^{\prime}\left(b_{\ell}\right) b_{\ell}+\alpha_{\ell}\left(b_{\ell}\right)
$$


Hence, $\beta_{3}>\beta_{1}$, and conditions (35)-(38) are not mutually exclusive and Corollary 2 holds for type dependent liquidity risk.

\section{Secondary market}

In this appendix, we provide a microfoundation for the secondary market at $t=1$ such that the asset price satisfies $P=\delta Q$, where $Q$ is the average quality of the liquidated assets and $\delta<1$ a constant discount. Suppose that, in addition to the borrowers and lenders in the main text, there is a third group of risk neutral but short-termist outsiders of measure 1 who have a perishable endowment of $W$ at each date $t=0,1,2$. These agents are shorttermist in the sense that they have discount factor $\delta<1$ per period and they are outsiders in the sense that they cannot distinguish assets of different quality at $t=1$.

At $t=0$, we assume that the outsiders find it optimal to consume their endowment instead of lending at the risk-free rate of $r$; together with the assumption of a sufficiently large discount in the main text, this requires $\delta<\min \{(1+r) / Q, 1 /(1+r)\}$, i.e. that the outsiders are sufficiently short-termist. At $t=1$, outsiders choose to provide liquidity equal to $M$ to buy liquidated assets in the secondary market at price $P$, and consume the rest $c_{1}=W-M$. At $t=2$, these $M / P$ units of purchased assets generate on average $Q$ per unit, hence outsiders consume $c_{2}=W+Q M / P .^{32}$ The equilibrium in the secondary market at $t=1$ is defined by liquidity $M$ and price $P$ such that

1. Outsiders maximize their utility for given $P: 33$

$$
\begin{aligned}
\max _{M \in[0, W]} U & =c_{1}+\delta c_{2} \\
\text { s.t. } & c_{1}=W-M \\
& c_{2}=W+Q M / P
\end{aligned}
$$

2. The secondary market clears:

$$
M=P \times \underbrace{\left(\alpha\left(b_{h}\right)\left(D_{h}+e\right)+\alpha\left(b_{\ell}\right)\left(D_{\ell}+e\right)\right)}_{\text {quantity of liquidated assets }}
$$

\footnotetext{
${ }^{32}$ Note that with the addition of the outsiders, aggregate consumption increases by $W$ in each period $t=0,1,2$. Hence this additional endowment does not affect our analysis of output $Y$.

${ }^{33}$ Recall that we assumed outsiders only observe the average quality $Q$. Note also that $Q$ is "predetermined" at $t=1$, and can thus be treated as an exogenous parameter when outsiders make the optimal decision. We assume $W$ large enough to rule out corner solutions.
} 
The first-order condition of the outsiders' optimization is

$$
-1+\delta Q / P=0
$$

which implies $P=\delta Q$. Substituting this into the market-clearing condition and using the definition of $Q$ in equation (2), we have the equilibrium provision of liquidity given by

$$
M=\delta\left(\alpha\left(b_{h}\right) R_{h}\left(D_{h}+e\right)+\alpha\left(b_{\ell}\right) R_{\ell}\left(D_{\ell}+e\right)\right)
$$

which solves the model.

\section{Endogenous equity}

In the main text, we assume that borrowers have exogenous equity $e$ and only choose leverage $b$. In this appendix, we consider the case where borrowers choose both equity and leverage. We show that this complicates the analysis but does not fundamentally alter the results.

In Section 3 we show that the borrower's objective function is linear in equity $e$. For an interior optimum, we therefore need a convex cost of equity $\kappa(e)$. The objective function then becomes

$$
e \times\left[R_{i} b-(1+r)(b-1)-\alpha(b)\left(R_{i}-P\right) b\right]-\kappa(e) .
$$

The first-order condition with respect to leverage $b$ is unaffected and remains as in equation (5). This implies that all our results on the responses of leverage to $r$ and $P$ and how they differ across types remain unchanged (Propositions 1,2 and 3).

The first-order condition with respect to equity pins down $e$ as a function of optimal leverage $b$, as well as $r$ and $P$ :

$$
R_{i} b-(1+r)(b-1)-\alpha(b)\left(R_{i}-P\right) b=\kappa^{\prime}(e)
$$

Since the LHS is greater for high types, we have that high types choose not only higher leverage but also higher equity, $e_{h}>e_{\ell}$. In terms of the responses of $e$ to $r$ and $P$, we have the same comparative statics as for leverage $b$; optimal equity is decreasing in the interest rate $r$ and increasing in the secondary market price $P$ :

$$
\frac{\partial e_{i}}{\partial r}=-\frac{b_{i}-1}{\mathcal{K}^{\prime \prime}\left(e_{i}\right)}<0 \quad \text { and } \quad \frac{\partial e_{i}}{\partial P}=\frac{\alpha\left(b_{i}\right) b_{i}}{\mathcal{K}^{\prime \prime}\left(e_{i}\right)}>0
$$


Further, at the optimal leverage, we have $\partial e / \partial b=0$. Considering the difference in responses across types, we can have the same heterogeneity in response as for leverage, i.e. $e_{h}$ responding less to $r$ than $e_{\ell}$ and more to $P$, if

$$
\left|\frac{\partial e_{h}}{\partial r}\right|<\left|\frac{\partial e_{\ell}}{\partial r}\right| \Leftrightarrow \frac{b_{h}-1}{\mathcal{K}^{\prime \prime}\left(e_{h}\right)}<\frac{b_{\ell}-1}{\mathcal{K}^{\prime \prime}\left(e_{\ell}\right)}
$$

and

$$
\frac{\partial e_{h}}{\partial P}>\frac{\partial e_{\ell}}{\partial P} \Leftrightarrow \frac{\alpha\left(b_{h}\right) b_{h}}{\kappa^{\prime \prime}\left(e_{h}\right)}>\frac{\alpha\left(b_{h}\right) b_{\ell}}{\mathcal{K}^{\prime \prime}\left(e_{\ell}\right)}
$$

With $b_{h}>b_{\ell}$ and therefore $\alpha\left(b_{h}\right)>\alpha\left(b_{\ell}\right)$, conditions (40) and (41) are both satisfied for intermediate values of the ratio $\kappa^{\prime \prime}\left(e_{h}\right) / \kappa^{\prime \prime}\left(e_{\ell}\right)$ :

$$
\frac{b_{h}-1}{b_{\ell}-1}<\frac{\kappa^{\prime \prime}\left(e_{h}\right)}{\mathcal{K}^{\prime \prime}\left(e_{\ell}\right)}<\frac{\alpha\left(b_{h}\right) b_{h}}{\alpha\left(b_{\ell}\right) b_{\ell}}
$$

Such intermediate values are possible as long as $b_{h}$ is s sufficiently larger than $b_{\ell}$ such that $\alpha\left(b_{h}\right) \gg \alpha\left(b_{\ell}\right)$.

We now turn to the analysis of monetary policy in Section 4 . In the main text, we focus on the effect monetary policy has on output through the quality of investment, $q$. However, note that with endogenous equity, there can also be a direct effect on total investment:

$$
\frac{d I}{d L}=1+\frac{d e_{h}}{d L}+\frac{d e_{\ell}}{d L}
$$

Similar to several objects in the main text, the effect of $L$ on $e$ can be decomposed into the response of $e$ to $r$ and the effect of $L$ on $r$, where the latter is the 'stimulus pass-through' term that also appears in other objects in the main text:

$$
\frac{d e_{i}}{d L}=\frac{d e_{i}}{d r} \times \frac{d r}{d L}
$$

Also similar to other objects in the main text, the effect of $L$ on $r$ can be decomposed into a direct effect and an indirect effect through $P:{ }^{34}$

$$
\frac{d e_{i}}{d r}=\underbrace{\frac{\partial e_{i}}{\partial r}}_{\text {direct effect }}+\underbrace{\frac{\partial e_{i}}{\partial P} \times \frac{d P}{d r}}_{\text {indirect effect }}
$$

Given the comparative statics for $e$, endogenizing equity can result in a larger or smaller increase in total investment. Endogenous equity dampens the increase in investment, di-

\footnotetext{
${ }^{34}$ Since we have $\partial e / \partial b=0$ at the optimal $b$, there are no additional terms involving $b$.
} 
rectly hampering monetary policy, if $d e_{i} / d r>0$, i.e. if the indirect effect through $P$ outweighs the direct effect through $r$ :

$$
\frac{\partial e_{i}}{\partial P} \frac{d P}{d r}>-\frac{\partial e_{i}}{\partial r}
$$

From (39) we have a sufficient condition given by

$$
\frac{d P}{d r}>\frac{b_{h}-1}{\alpha\left(b_{h}\right) b_{h}} .
$$

Consider now the effect monetary policy has on output through the quality of investment $q$. With endogenous and heterogeneous equity, $q$ becomes

$$
q=\frac{R_{h}\left(D_{h}+e_{h}\right)+R_{\ell}\left(D_{\ell}+e_{\ell}\right)}{\left(D_{h}+e_{h}\right)+\left(D_{\ell}+e_{\ell}\right)}=\frac{R_{h} b_{h} e_{h}+R_{\ell} b_{\ell} e_{\ell}}{b_{h} e_{h}+b_{\ell} e_{\ell}} .
$$

Comparing this to the expression (1) in the main text, we see that expression (42) has the product of leverage and equity, $b_{i} e_{i}$, where expression (1) has only leverage $b_{i}$. Endogenizing equity therefore can change results only if the response of $b_{i} e_{i}$ to $r$ (directly) and $P$ (indirectly) is different from the response of $b_{i} \cdot{ }^{35}$ We have

$$
\begin{aligned}
\frac{d}{d r}\left(e_{i} b_{i}\right) & =e_{i} \times \frac{d b_{i}}{d r}+b_{i} \times \frac{d e_{i}}{d r} \\
& =\underbrace{e_{i} \times \frac{\partial b_{i}}{\partial r}+b_{i} \times \frac{\partial e_{i}}{\partial r}}_{\text {direct effects }}+\underbrace{e_{i} \times \frac{\partial b_{i}}{\partial P} \frac{d P}{d r}+b_{i} \times \frac{\partial e_{i}}{\partial P} \frac{d P}{d r}}_{\text {indirect effects }}
\end{aligned}
$$

Consider first the direct effects of $r$. In the main text, the results derive from the fact that high types' leverage responds less to $r$ than low types, $\left|\partial b_{h} / \partial r\right|<\left|\partial b_{\ell} / \partial r\right|$ (Proposition 2). Equation (43) shows that endogenizing equity can attenuate these effects since $e_{h}>e_{\ell}$ and, potentially, $b_{h}\left|\partial e_{h} / \partial r\right|>b_{\ell}\left|\partial e_{\ell} / \partial r\right|$. Consider next the indirect effects through $P$. In the main text, the results derive from the fact that high types' leverage can respond more to $P$ than low types, $\partial b_{h} / \partial P>\partial b_{\ell} / \partial P$ (Proposition 3). Equation (43) shows that endogenizing equity can strengthen these effects for $\partial e_{h} / \partial P>\partial e_{\ell} / \partial P$.

In sum, endogenizing equity opens the possibility of a further dampening of monetary policy via the extensive margin of investment for situations where the feedback effect through the liquidation value is strong. Further, along the intensive margin, endogenizing equity leads to two competing effects where the direct effect of $r$ on quality is attenuated

\footnotetext{
${ }^{35}$ This also applies to stimulus pass-through $d r / d L$ where we now have to consider $d\left(b_{i} e_{i}\right) / d r$ instead of $d b_{i} / d r$.
} 
while the indirect effect through $P$ is strengthened. Again, endogenous equity exacerbates the impairment of monetary policy especially for cases where the lemons spiral is strong which is the case during the type of stressed periods we are interested in. 